\title{
Transplacental pharmacokinetic model of digoxin based on ex vivo human placental perfusion
}

study

Ken Kurosawa, Saki Noguchi, Tomohiro Nishimura, Masatoshi Tomi and Koji Chiba

Department of Japan-Clinical Pharmacology \& Pharmacometrics, Janssen Pharmaceutical K.K.,

Tokyo, Japan (K.K.); Laboratory of Clinical Pharmacology, Yokohama University of Pharmacy,

Kanagawa, Japan (K.C.); Faculty of Pharmacy, Keio University of Pharmacy, Tokyo, Japan (K.K.,

S.N., T.N., M.T.) 
Running Title: Ex vivo human transplacental PK model of digoxin

Please address correspondence to: Koji Chiba, Ph.D

Laboratory of Clinical Pharmacology, Yokohama University of Pharmacy, 601 Matano-cho,

Totsuka-ku, Yokohama-shi, Kanagawa 245-0066, Japan, Tel: +81-(0)45-859-1300 FAX:

+81-(0)45-859-1301, E-mail: k.chiba@hamayaku.ac.jp

\section{Number of}

Text pages: 56

Tables: 1

Figures: 8

References: 70

Words in Abstract: 250

Words in Introduction: 513

Words in Discussion: 1500 


\section{List of nonstandard abbreviations}

AUC, area under the plasma concentration-time curve; BCS, biopharmaceutics classification system;

$\mathrm{BM}$, basal plasma membrane; $\mathrm{C}_{\mathrm{fc}}$, drug concentration in fetal capillaries; $\mathrm{C}_{\mathrm{fr}}$, drug concentration in fetal reservoir; $\mathrm{CI}$, confidence interval; $\mathrm{C}_{\mathrm{ma}}$, drug concentration in maternal artery; $\mathrm{C}_{\max }$, maximum drug concentration; $\mathrm{C}_{\mathrm{mp}}$, drug concentration in maternal placenta; $\mathrm{C}_{\mathrm{mv}}$, drug concentration in maternal vein; $\mathrm{C}_{\mathrm{np}}$, drug concentration in non-perfused tissue; $\mathrm{C}_{\mathrm{t}}$, drug concentration in syncytiotrophoblast; $\mathrm{C}_{\mathrm{ua}}$, drug concentration in umbilical artery; $\mathrm{C}_{\mathrm{uv}}$, drug concentration in umbilical vein; CYP, cytochrome P450; DDI, drug-drug interaction; F:M, fetal-to-maternal drug concentration ratio; $\mathrm{I}_{\mathrm{t}}$, inhibitor concentration in syncytiotrophoblast; $\mathrm{Kp}_{\mathrm{s}-\mathrm{m}}$, syncytiotrophoblast to maternal reservoir concentration ratio; $\mathrm{K}_{\mathrm{i}, \mathrm{BM}}$, inhibition constant for the efflux transporter at the $\mathrm{BM}$; $\mathrm{K}_{\mathrm{i}, \mathrm{BM}, \mathrm{QND}}, \mathrm{K}_{\mathrm{i}, \mathrm{BM}}$ of quinidine; $\mathrm{K}_{\mathrm{i}, \mathrm{BM}, \mathrm{VRP}}, \mathrm{K}_{\mathrm{i}, \mathrm{BM}}$ of verapamil; $\mathrm{K}_{\mathrm{i}, \mathrm{MDR} 1}$, inhibition constant for multidrug resistance protein 1 at the microvillous plasma membrane; $\mathrm{K}_{\mathrm{i}, \mathrm{MDR} 1, \mathrm{QND}}, \mathrm{K}_{\mathrm{i}, \mathrm{MDR} 1}$ of quinidine; $\mathrm{K}_{\mathrm{i}, \mathrm{MDR} 1, \mathrm{VRP}}, \mathrm{K}_{\mathrm{i}, \mathrm{MDR} 1}$ of verapamil; MDR, multidrug resistance protein; mRNA, messenger ribonucleic acid; MVM, microvillous plasma membrane; OATP, organic anion transporting polypeptide; OCT, organic cation transporter; PAMPA, parallel artificial membrane permeation assay; PK, pharmacokinetics; SVT, supraventricular tachycardia; TDM, therapeutic drug monitoring; $\mathrm{t}_{\mathrm{ss}}$, time to achieve the steady state. 


\begin{abstract}
Digoxin is used as first-line therapy to treat fetal supraventricular tachycardia, though because of the
\end{abstract} narrow therapeutic window, it is essential to estimate digoxin exposure in the fetus. The data from $e x$ vivo human placental perfusion study are used to predict in vivo fetal exposure noninvasively, but the ex vivo fetal to maternal concentration $(\mathrm{F}: \mathrm{M})$ ratios observed in digoxin perfusion studies were much lower than those in vivo. In the present study, we developed a human transplacental pharmacokinetic model of digoxin using previously reported ex vivo human placental perfusion data. The model consists of maternal intervillous, fetal capillary, non-perfused tissue and syncytiotrophoblast compartments, with multidrug resistance protein (MDR) 1 and influx transporter at the microvillous membrane (MVM) and influx and efflux transporters at the basal plasma membrane (BM). The model-predicted F:M ratio was 0.66 , which is consistent with the mean in vivo value of 0.77 (95\% confidence interval: $0.64-0.91)$. The time to achieve the steady state from the ex vivo perfusion study was estimated as 1,500 min, which is considerably longer than the reported ex vivo experimental durations, and this difference is considered to account for the inconsistency between ex vivo and in vivo F:M ratios. Reported digoxin concentrations in a drug-drug interaction study with MDR1 inhibitors quinidine and verapamil were consistent with the profiles simulated by our model incorporating inhibition of efflux transporter at the BM in addition to MVM. Our modeling and simulation approach should be a powerful tool to predict fetal exposure and DDIs in human placenta. 


\section{Significance Statement}

We developed a human transplacental pharmacokinetic model of digoxin based on ex vivo human

placental perfusion studies in order to resolve inconsistencies between reported ex vivo and in vivo

fetal to maternal concentration ratios. The model successfully predicted the in vivo fetal exposure to

digoxin and the drug-drug interactions of digoxin and P-glycoprotein/multidrug resistance protein 1

inhibitors in human placenta. 


\section{Introduction}

Digoxin is a cardiac glycoside extracted from the leaves of Digitalis lanata (Tantivatana and Wright, 1958). It has been used for many years to treat heart disease (Ziff et al., 2015), but therapeutic drug monitoring (TDM) is recommended because of serious adverse effects resulting from even small exposure changes (Beller et al., 1971; Ragab, 2012). In obstetrics, transplacental treatment of pregnant women with digoxin has been used to manage fetal supraventricular tachycardia (SVT) as first-line therapy (Strzelecka et al., 2017; Miyoshi et al., 2019). When digoxin is administered to pregnant women, dose escalation is recommended because pregnancy alters the drug disposition towards lower levels (Martin-Suarez et al., 2017), but it remains challenging to maximize the fetal efficacy of digoxin while minimizing the maternal adverse effects (Malhamé et al., 2019). Thus, it is crucial to predict in vivo fetal exposure of digoxin based on its transfer characteristics across the human placenta.

Ex vivo human placental perfusion study is a valuable tool to predict in vivo fetal exposure (Myren et al., 2007). Hutson et al. (2011) proposed a method to predict the in vivo fetal to maternal concentration (F:M) ratio from ex vivo data. Their predicted F:M ratios for twenty-four drugs were generally consistent with the in vivo F:M ratios, except for four drugs. Digoxin was one of the exceptions, with a predicted F:M ratio much lower than the in vivo ratio. Hutson et al. (2011) 
suggested that the inconsistency between in vivo and ex vivo F:M ratios might be associated with efflux transport via multidrug resistance protein 1 (MDR1/P-glycoprotein/ABCB1) expressed at the microvillous plasma membrane (MVM) of human placental syncytiotrophoblasts (Ushigome et al., 2003; Ceckova-Novotna et al., 2006). Indeed, digoxin is a typical substrate of MDR1 (Tanigawara et al., 1992; Troutman and Thakker, 2003), and MDR1 inhibitors were reported to alter digoxin uptake by MVM vesicles obtained from normal human term placenta (Ushigome et al., 2003). However, an ex vivo human placental perfusion study failed to find a significant effect of MDR1 inhibitors such as quinidine and verapamil on the transplacental transfer of digoxin (Holcberg et al., 2003), even though ex vivo perfusion studies have successfully demonstrated the involvement of placental MDR1 in suppressing fetal transfer and drug-drug interactions (DDIs) of drugs such as indinavir, vinblastine (Sudhakaran et al., 2008), lopinavir (Ceccaldi et al., 2009), methadone, paclitaxel (Nanovskaya et al., 2005), and saquinavir (Mölsä et al., 2005). Accordingly, quantitative assessment of the interaction of digoxin with MDR1 inhibitors is needed to determine the contribution of MDR1 to the suppression of fetal digoxin transfer and to understand the reason for the inconsistency between in vivo and ex vivo studies.

A human transplacental pharmacokinetic (PK) model incorporating parameters of passive and active (transporter-mediated) transmembrane transfers estimated from ex vivo human placenta perfusion 
studies can generate quantitative insights into the mechanisms governing the fetal transfer of drugs

(Kurosawa et al., 2020). Therefore, the purpose of this present study was to develop a human transplacental PK model of digoxin in order to predict in vivo fetal exposure to digoxin and digoxin DDIs at MDR1 in the human placenta. 


\section{Materials and Methods}

A schematic diagram illustrating the development of the transplacental PK model to predict DDIs of digoxin in the human placenta and in vivo fetal exposure to digoxin is shown in Fig. 1. The procedure consisted of the following four steps: i) model construction, ii) verification of the model for different experimental conditions, iii) prediction of DDIs of digoxin and MDR1 inhibitors, iv) confirmation for in vivo fetal exposure. In the first step, the model was constructed by fitting to reported digoxin concentration-time profiles obtained in an ex vivo human placental perfusion study with a closed system (Derewlany et al., 1991). Next, verification was conducted by applying the model to data obtained under different experimental conditions (Holcberg et al., 2003). Then, interactions of digoxin with quinidine or verapamil in an ex vivo human placental perfusion study (Holcberg et al., 2003) were predicted using the developed model. For the DDI predictions, a transplacental PK model of quinidine was also developed using reported quinidine concentration-time profiles obtained in an ex vivo human placental perfusion study with a closed system (Tsadkin-tamir, 2005). For the prediction of DDI with verapamil, the initial verapamil concentration was assumed to be maintained throughout the perfusion study. Finally, the predicted F:M ratios from the digoxin transplacental PK model were compared with reported in vivo values (Rogers et al., 1972; Chan et al., 1978; Nagashima et al., 1986; Zhou et al., 2011). 


\section{Development of the Transplacental PK Model of Digoxin}

The digoxin transplacental PK model (Fig. 2(A)) was constructed based on our previous model for metformin (Kurosawa et al., 2020), with the modification of adding a non-perfused placental tissue compartment (Figs. 2(A) and (B)). In a typical human placental perfusion experiment using a single cotyledon, non-perfused regions, which are parts of cotyledon adjacent to the perfused single cotyledon (Fig. 2(B)), remain (Mathiesen et al., 2010; Grafmüller et al., 2013). In the reported perfusion study (Derewlany et al., 1991), the digoxin concentrations and weights of the perfused cotyledon and the non-perfused tissue were measured following the perfusion. Therefore, the non-perfused tissue compartment was incorporated into the transplacental PK model separately from the maternal placental compartment (Fig. 2(A)).

As observed data for fitting, we obtained the time and the digoxin concentrations in maternal artery, maternal vein, umbilical artery, umbilical vein, perfused placental tissue (syncytiotrophoblast), and non-perfused placental tissue from the tables and figures published in the report of the ex vivo human placental perfusion study (Derewlany et al., 1991) by using WebPlotDigitizer Version 4.4 (https://automeris.io/WebPlotDigitizer). In that study, a closed perfusion system was applied to a single cotyledon subdivided from the normal-term human placenta at delivery. The medium was perfused at flow rates of $Q_{m}$ for the maternal circuit and $Q_{f}$ for the fetal circuit (Table 1). Digoxin 
(Lanoxin ${ }^{\circledR}$ ) at the initial concentration of $5.5 \mathrm{ng} / \mathrm{mL}$ (digitized from the reported figure) in the maternal reservoir was recirculated in the maternal and fetal circuits for $180 \mathrm{~min}$. The differential equations of the digoxin transplacental PK model are as follows (Eqs. (1) to (10)):

$$
V_{m r} \times \frac{\mathrm{d} C_{m r}}{\mathrm{dt}}=Q_{m} \times\left(C_{m v}-C_{m r}\right)
$$

$$
V_{m a} \times \frac{\mathrm{d} C_{m a}}{\mathrm{dt}}=Q_{m} \times\left(C_{m r}-C_{m a}\right)
$$

$$
V_{m p} \times \frac{\mathrm{d} C_{m p}}{\mathrm{dt}}=\left(C_{m a}-C_{m p}\right) \times Q_{m}+\left(P S_{M V M, a c t, e f f}+P S_{M V M, d i f f}\right) \times f_{u, t} \times C_{t}-\left(P S_{M V M, a c t, i n f}+\right.
$$$$
\left.P S_{M V M, \text { diff }}\right) \times f_{u, \text { med }} \times C_{m p}-Q_{n p} \times\left(f_{u, m e d} \times C_{m p}-f_{u, n p} \times C_{n p}\right)
$$

$$
V_{m v} \times \frac{\mathrm{d} C_{m v}}{\mathrm{dt}}=Q_{m} \times\left(C_{m p}-C_{m v}\right)
$$

$$
\begin{aligned}
& V_{t} \times \frac{\mathrm{d} C_{t}}{\mathrm{dt}}=\left(P S_{M V M, a c t, i n f}+P S_{M V M, d i f f}\right) \times f_{u, \text { med }} \times C_{m p}+\left(P S_{B M, a c t, i n f}+P S_{B M, d i f f}\right) \times f_{u, \text { med }} \times \\
& C_{f c}-\left(P S_{M V M, a c t, e f f}+P S_{M V M, \text { diff }}+P S_{B M, a c t, e f f}+P S_{B M, \text { diff }}\right) \times f_{u, t} \times C_{t}
\end{aligned}
$$

$$
V_{n p} \times \frac{\mathrm{d} C_{n p}}{\mathrm{dt}}=Q_{n p} \times\left(f_{u, \text { med }} \times C_{m p}-f_{u, n p} \times C_{n p}\right)
$$




$$
\begin{aligned}
& V_{f c} \times \frac{\mathrm{d} C_{f c}}{\mathrm{dt}}=Q_{f} \times\left(C_{u a}-C_{f c}\right)+\left(P S_{B M, a c t, e f f}+P S_{B M, d i f f}\right) \times f_{u, t} \times C_{t}-\left(P S_{B M, a c t, i n f}+\right. \\
& \left.P S_{B M, \text { diff }}\right) \times f_{u, \text { med }} \times C_{f c}
\end{aligned}
$$

$V_{u v} \times \frac{\mathrm{d} C_{u v}}{\mathrm{dt}}=Q_{f} \times\left(C_{f c}-C_{u v}\right)$

$$
V_{f r} \times \frac{\mathrm{d} C_{f r}}{\mathrm{dt}}=Q_{f} \times\left(C_{u v}-C_{f r}\right)
$$

$$
V_{u a} \times \frac{\mathrm{d} C_{u a}}{\mathrm{dt}}=Q_{f} \times\left(C_{f r}-C_{u a}\right)
$$

Where $\mathrm{C}_{\mathrm{mr}}, \mathrm{C}_{\mathrm{ma}}, \mathrm{C}_{\mathrm{mp}}, \mathrm{C}_{\mathrm{mv}}, \mathrm{C}_{\mathrm{t}}, \mathrm{C}_{\mathrm{np}}, \mathrm{C}_{\mathrm{fc}}, \mathrm{C}_{\mathrm{uv}}, \mathrm{C}_{\mathrm{fr}}$, and $\mathrm{C}_{\mathrm{ua}}$ represent the total digoxin concentrations in the maternal reservoir $\left(C_{m r}\right)$, maternal artery $\left(C_{m a}\right)$, maternal placenta $\left(C_{m p}\right)$, maternal vein $\left(C_{m v}\right)$, syncytiotrophoblast $\left(\mathrm{C}_{\mathrm{t}}\right)$, non-perfused placental tissue $\left(\mathrm{C}_{\mathrm{np}}\right)$, fetal capillary $\left(\mathrm{C}_{\mathrm{fc}}\right)$, umbilical vein $\left(\mathrm{C}_{\mathrm{uv}}\right)$, fetal reservoir $\left(\mathrm{C}_{\mathrm{fr}}\right)$, and umbilical artery $\left(\mathrm{C}_{\mathrm{ua}}\right)$ compartments. At time 0 min (the start of digoxin perfusion), $\mathrm{C}_{\mathrm{mr}}$ was $5.5 \mathrm{ng} / \mathrm{mL}$, and other parameters were fixed to be $0 \mathrm{ng} / \mathrm{mL} . \mathrm{V}_{\mathrm{mr}}, \mathrm{V}_{\mathrm{ma}}$, $\mathrm{V}_{\mathrm{mp}}, \mathrm{V}_{\mathrm{mv}}, \mathrm{V}_{\mathrm{t}}, \mathrm{V}_{\mathrm{np}}, \mathrm{V}_{\mathrm{fc}}, \mathrm{V}_{\mathrm{uv}}, \mathrm{V}_{\mathrm{fr}}$, and $\mathrm{V}_{\mathrm{ua}}$ are the volumes of the maternal reservoir $\left(\mathrm{V}_{\mathrm{mr}}\right)$, sampling port of the maternal artery $\left(\mathrm{V}_{\mathrm{ma}}\right)$, maternal placenta $\left(\mathrm{V}_{\mathrm{mp}}\right)$, sampling port of the maternal vein $\left(\mathrm{V}_{\mathrm{mv}}\right)$, syncytiotrophoblast $\left(\mathrm{V}_{\mathrm{t}}\right)$, non-perfused placental tissue $\left(\mathrm{V}_{\mathrm{np}}\right)$, fetal capillary $\left(\mathrm{V}_{\mathrm{fc}}\right)$, sampling port of the umbilical vein $\left(\mathrm{V}_{\mathrm{uv}}\right)$, fetal reservoir $\left(\mathrm{V}_{\mathrm{fr}}\right)$, and sampling port of the umbilical artery $\left(\mathrm{V}_{\mathrm{ua}}\right) . \mathrm{V}_{\mathrm{mp}}$ is 
the sum of the volume of the perfusion medium in the maternal chamber $\left(\mathrm{V}_{\mathrm{ch}}\right)$ and maternal intervillous volume $\left(\mathrm{V}_{\mathrm{mi}}\right)$ (Kurosawa et al., 2020). $\mathrm{f}_{\mathrm{u}, \mathrm{med}}, \mathrm{f}_{\mathrm{u}, \mathrm{np}}$, and $\mathrm{f}_{\mathrm{u}, \mathrm{t}}$ denote the unbound fractions of digoxin in the medium of maternal and fetal circuits $\left(f_{u, m e d}\right)$, the non-perfused placental tissue $\left(f_{u, n p}\right)$, and the syncytiotrophoblast $\left(f_{u, t}\right) . Q_{n p}$ is the intercompartmental clearance between the maternal placenta and non-perfused placental tissue.

The passive clearances of digoxin in the MVM ( $\left.\mathrm{PS}_{\mathrm{MVM}, \mathrm{diff}}\right)$ and the basal plasma membrane (BM,

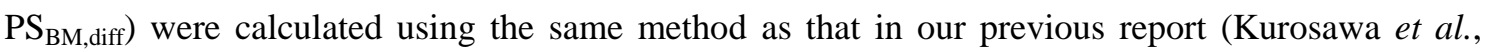
2020). The calculations are described in detail in Supplemental Text and Supplemental Table 1.

Because digoxin is not extensively metabolized, no metabolic clearance was assumed in the model.

Active influx and efflux clearances through the MVM ( $\mathrm{PS}_{\mathrm{MVM} \text {,act,inf }}$ and $\mathrm{PS}_{\mathrm{MVM} \text {,act,eff, }}$ respectively) and $\mathrm{BM}\left(\mathrm{PS}_{\mathrm{BM}, \mathrm{act}, \text { inf }}\right.$ and $\mathrm{PS}_{\mathrm{BM}, \text { act,eff, }}$, respectively) were assumed to be involved in the transport of digoxin.

The physicochemical properties of digoxin, the experimental conditions of the ex vivo perfusion study, and the physiological PK parameters in the model are listed in Table 1.

The model fitting was performed using NONMEM ${ }^{\circledR}$ version 7.4 (Icon Development Solutions, 
Ellicott City, MD, USA; Beal and Sheiner, 1989) with nonlinear least-squares regression. The R Project for Statistical Computing, Version 3.5.2 for Windows (Comprehensive R Network, http://cran.r-project.org) was used for the graphics generation, post-processing of NONMEM ${ }^{\circledR}$, and statistical analysis.

\section{Verification of the Human Transplacental PK Model for Digoxin}

The transplacental PK model constructed by using the data of Derewlany et al. (1991) was applied to other ex vivo perfusion studies in different experimental settings, reported by Holcberg et al. (2003).

The simulation of $\mathrm{C}_{\mathrm{ma}}$ and $\mathrm{C}_{\mathrm{uv}}$ was performed using the same model. The physicochemical properties of digoxin, the physiological parameters of human placental cotyledon, and the experimental conditions used for the model verification are listed in Supplemental Table 2.

\section{Model Prediction of DDIs between Digoxin and MDR1 Inhibitors}

Digoxin is a substrate of MDR1 (Fenner et al., 2009) at the MVM (Ushigome et al., 2003;

Ceckova-Novotna et al., 2006) and is transported from syncytiotrophoblasts to the maternal side

(Nekhayeva et al., 2006; Sudhakaran et al., 2008). Holcberg et al. (2003) examined the DDIs of digoxin with MDR1 inhibitors quinidine and verapamil, even though no inhibition was observed in the perfusion studies. To quantitatively assess the DDIs of digoxin and these inhibitors, simulations 
were performed using the developed transplacental PK model of digoxin with the following equation (Eq. (11)).

$P S_{M V M, \text { act }, \text { eff }(+ \text { inhibitor })}=\frac{P S_{M V M, a c t, e f f}}{1+\frac{f u, t \times I_{t}}{K_{i, M D R 1, M V M}}}$

Where $\mathrm{I}_{\mathrm{t}}$ and $\mathrm{K}_{\mathrm{i}, \mathrm{MDR} 1, \mathrm{MVM}}$ represent the total inhibitor concentration in syncytiotrophoblast and the inhibition constant for MDR1 at the MVM, respectively. For $\mathrm{K}_{\mathrm{i}, \mathrm{MDR} 1, \mathrm{MVM}}$ of quinidine $\left(\mathrm{K}_{\mathrm{i}, \mathrm{MDR} 1, \mathrm{MVM}, \mathrm{QND}}\right)$ and verapamil $\left(\mathrm{K}_{\mathrm{i}, \mathrm{MDR} 1, \mathrm{MVM}, \mathrm{VRP}}\right)$, the values obtained in in vitro studies (Chaudhry et al., 2018) were used (Supplemental Table 2).

It was assumed that quinidine and verapamil were not metabolized in the ex vivo human placental perfusion studies. Quinidine is mainly metabolized by cytochrome P450 (CYP) 3A4 (Nielsen et al., 1999) and verapamil by CYP3A4/5 and CYP2C8 (Tracy et al., 1999). However, messenger ribonucleic acid (mRNA) and protein expression levels of these enzymes are low or undetectable in human placenta (Hakkola et al., 1996; Bieche et al., 2007). Thus, no metabolic clearance was incorporated in the present model of quinidine, and this was also assumed to be the case for verapamil in the DDI simulation studies. 
The transplacental PK model of quinidine (Fig. 2(A)) was constructed using the quinidine concentrations in the maternal artery, umbilical vein, and syncytiotrophoblast taken from the previously reported ex vivo human placental perfusion study (Tsadkin-tamir, 2005). In that study, a closed perfusion system was applied to a single cotyledon obtained from normal-term human placenta at delivery. The experimental settings for the quinidine transplacental PK model are summarized in Supplemental Table 3. The $\mathrm{PS}_{\mathrm{MVM} \text {,diff }}$ and $\mathrm{PS}_{\mathrm{BM} \text {,diff }}$ of quinidine were calculated using the same method as employed for the digoxin model (Supplemental Text). PS $\mathrm{MVM}_{\text {,act,inf, }}$ $\mathrm{PS}_{\mathrm{MVM}, \text { act,eff, }} \mathrm{PS}_{\mathrm{BM}, \text { act,inf }}$ and $\mathrm{PS}_{\mathrm{BM}, \text { act,eff }}$ were also assumed to influence the active transport of quinidine in the human placenta in the model construction. The same data collection methods and model fitting as in the case of digoxin were used for the quinidine model development.

As for verapamil, the initial concentration of $250 \mathrm{ng} / \mathrm{mL}$ in the maternal circuit was assumed to be maintained throughout the DDI study. $\mathrm{I}_{\mathrm{t}}$ of verapamil was calculated using the syncytiotrophoblast to maternal reservoir concentration ratio $\left(\mathrm{Kp}_{\mathrm{s}-\mathrm{m}}\right)$ of 0.97 , obtained in a macaque study (Eyal et al., 2009), as the interhaemal barrier of rhesus monkey is considered analogous to that of humans (Panigel et al., 1975; Grigsby, 2016). A sensitivity analysis showed that $\mathrm{Kp}_{\mathrm{s}-\mathrm{m}}$ values between $0.3-3$ had almost no effect on the digoxin PK profile in the DDI study (data not shown). 
The physicochemical properties of quinidine and verapamil, the physiological parameters of human placental cotyledon, and the experimental conditions used for the DDI predictions of digoxin with quinidine or verapamil are summarized in Supplemental Table 2.

\section{Model Prediction of in vivo Fetal Digoxin Exposure}

To predict in vivo fetal exposure to digoxin, $\mathrm{C}_{\mathrm{ma}}$ and $\mathrm{C}_{\mathrm{uv}}$ at the steady state were simulated by the developed transplacental PK model for the experimental conditions used in the ex vivo perfusion study by Derewlany et al. (1991). For the in vivo prediction, the $\mathrm{f}_{\mathrm{u}, \mathrm{med}}(=0.67$ for mother and fetus) of digoxin in humans under physiological conditions (Hubert et al., 1985; Hebert et al., 2008) was used. To predict in vivo F:M ratio, it is hypothesized that F:M ratio obtained from a single cotyledon is corresponding to that of whole placenta consisted of approximately 15-30 cotyledons (Gundalli et al., 2015). Then, the ratios of the simulated steady-state $C_{u v}$ and $C_{m a}$ values were used as the predicted in vivo F:M ratios. The predicted in vivo F:M ratios were compared with the in vivo F:M ratio integrated from multiple clinical reports (Rogers et al., 1972; Chan et al., 1978; Nagashima et al., 1986; Zhou et al., 2011) by using the Dersimonian and Laird method (Dersimonian and Laird, 1986). The clinical information from the multiple reports of in vivo $\mathrm{F}: \mathrm{M}$ ratios are summarized in

\section{Supplemental Table 4.}


To predict in vivo fetal exposures to digoxin in the presence of the MDR1 inhibitors quinidine and verapamil, the increase in maternal concentration of digoxin caused by inhibiting MDR1 in small intestine and kidney as well as placenta should be considered. Therefore, the maximum concentrations $\left(\mathrm{C}_{\max }\right)$ of drugs after oral administration of digoxin with/without quinidine at the therapeutic dosage to cardiac patients or verapamil (240 mg/day) to healthy volunteers in clinical DDI studies (Pedersen et al., 1983; Rodin et al., 1988) (listed in Supplemental Table 5) were also applied to the simulation of digoxin transplacental PK profiles using the developed model. 


\section{Results}

\section{Development of Digoxin Human Transplacental PK Model}

The human transplacental PK model for digoxin was developed using reported data obtained in a closed perfusion system of human placenta, which includes non-perfused tissue (Derewlany et al., 1991). The fitted profiles of digoxin concentration-time profiles for $C_{m a}, C_{m v}, C_{u v}, C_{u a}, C_{t}$, and $C_{n p}$ are shown in Figs. 3(A)-(C). The transplacental PK model well captured the observed concentrations of digoxin in the ex vivo study. The estimated parameters are listed in Table $1 . \mathrm{V}_{\mathrm{np}}$ was estimated as $49.6 \mathrm{~mL}$, which is consistent with the actual measured weight of non-perfused tissue (44.2 $\mathrm{g})$ reported by Derewlany et al. (1991).

\section{Verification of the Digoxin Human Transplacental PK Model}

The values of digoxin $\mathrm{C}_{\mathrm{ma}}$ and $\mathrm{C}_{\mathrm{uv}}$ previously obtained in an ex vivo closed perfusion experiment (Holcberg et al., 2003) were used to examine whether the developed transplacental model (Fig.

2(A)) is applicable to different ex vivo perfusion conditions. The observed $\mathrm{C}_{\mathrm{ma}}$ and $\mathrm{C}_{\mathrm{uv}}$ were well simulated by the developed model (Fig. 4).

The value of $11.5 \mathrm{~mL}$ for $\mathrm{V}_{\mathrm{ch}}$, which was estimated by fitting to the quinidine concentrations in the reported perfusion study (Tsadkin-tamir, 2005) as described below (see "Application of the 
developed model to ex vivo DDI studies") was used in the digoxin PK simulations of the digoxin perfusion and DDI studies (Holcberg et al., 2003). Because the $V_{\text {ch }}$ values may be different among perfusion studies, sensitivity analysis of $\mathrm{V}_{\mathrm{ch}}$ was performed. Holcberg et al. (2003) stated that the remaining medium in the chamber was kept at the lowest level on part of the placenta (42.66 g), which consisted of perfused cotyledon and non-perfused tissue. Therefore, in the sensitivity analysis, the lower and upper limit values of $\mathrm{V}_{\mathrm{ch}}$ were set at 0 (no remaining medium) and $50 \mathrm{~mL}$, respectively. The simulated values of $\mathrm{C}_{\mathrm{ma}}$ and $\mathrm{C}_{\mathrm{fv}}$ were well overlapped with the observed values in the digoxin perfusion study by Holcberg et al. (2003) (Fig. 4). Thus, the influence of variation of $\mathrm{V}_{\mathrm{ch}}$ can be neglected.

\section{Application of the developed model to ex vivo DDI studies}

The profiles simulated by the model incorporating influx and efflux transporters on both the MVM and $\mathrm{BM}$ were consistent with the reported digoxin concentration profiles. Therefore, the possibility of inhibition of these transporters by co-administrated drugs, especially MDR1 inhibitors, should be considered. However, Holcberg et al. (2003) observed no inhibition by quinidine or verapamil in an ex vivo placental DDI study of digoxin with the MDR1 inhibitors quinidine and verapamil in their ex vivo human placental perfusion system, which afforded the data used to verify our developed transplacental PK model for digoxin perfusion without inhibitors To consider the reasons for this 
negligible inhibitory effect, we applied our model to the reported DDI data (Holcberg et al., 2003).

For quinidine, the transplacental PK model was also constructed using data from a reported ex vivo human placental perfusion study of quinidine (Tsadkin-tamir, 2005), and fitted profiles of quinidine concentration-time for $\mathrm{C}_{\mathrm{ma}}, \mathrm{C}_{\mathrm{uv}}$, and $\mathrm{C}_{\mathrm{t}}$ are depicted in Supplemental Figures. 1(A)-(B). The estimated parameters of the quinidine model are summarized in Supplemental Table 3. The transplacental PK model for quinidine well reproduced the observed concentrations of quinidine in the ex vivo study. A static model for verapamil was applied for the DDI study of digoxin and verapamil since sufficient data were not available to construct a human placental PK model. Specifically, to avoid a false-negative prediction of DDI, it was assumed that the unbound syncytiotrophoblast concentration of verapamil of $41.2 \mathrm{ng} / \mathrm{mL}$, calculated from the maximum (initial) concentration of verapamil in the maternal circuit $(250 \mathrm{ng} / \mathrm{mL})$, was maintained statically (static model).

Since MDR1 is present at the MVM (Ushigome et al., 2003; Ceckova-Novotna et al., 2006), the efflux transporter of digoxin at the MVM is most likely MDR1. Therefore, simulations were performed with inhibition of MDR1 at the MVM by quinidine and verapamil based on the reported $\mathrm{K}_{\mathrm{i}, \mathrm{MDR} 1, \mathrm{MVM}, \mathrm{QND}}$ of 0.27 and $\mathrm{K}_{\mathrm{i}, \mathrm{MDR} 1, \mathrm{MVM}, \mathrm{VRP}}$ of $0.55 \mu \mathrm{M}$, respectively (Chaudhry et al., 2018). Furthermore, the efflux transporter of digoxin at the BM could also be sensitive to quinidine and 
verapamil, since MDR1 and/or MDR3, both of which accept digoxin as a substrate (Smith et al., 2000) and are sensitive to quinidine and verapamil (Schlemmer and Sirotnak, 1994; Aleo et al., 2017), are expressed at the BM of syncytiotrophoblasts and/or cytotrophoblast, adjacent to the BM of the syncytiotrophoblast (Evseenko et al., 2006, 2007; Lye et al., 2013; Kliman et al., 2018). Therefore, the simulations were performed in the presence and absence of inhibition of the efflux transporter at the BM by quinidine and verapamil, as shown in Fig. 5. Various $\mathrm{K}_{\mathrm{i}}$ values for the efflux transporter at the $\mathrm{BM}$ were set: $0.027 \mu \mathrm{M}$ (green lines), $0.27 \mu \mathrm{M}$ (blue lines) and $2.7 \mu \mathrm{M}$ (purple lines) for quinidine $\left(\mathrm{K}_{\mathrm{i}, \mathrm{BM}, \mathrm{QND}}\right)$ and $0.055 \mu \mathrm{M}$ (green lines), $0.55 \mu \mathrm{M}$ (blue lines), and 5.5 $\mu \mathrm{M}$ (purple lines) for verapamil $\left(\mathrm{K}_{\mathrm{i}, \mathrm{BM}, \mathrm{VRP}}\right)$, in addition to the case that $\mathrm{BM}$ transporters were insensitive to these drugs (orange lines). These values were chosen for sensitivity analyses, because the kinetic parameters of the efflux transporter at the BM are unknown. In the case of quinidine inhibition, the observed digoxin concentrations in the presence of quinidine were close to the simulated concentrations of digoxin with the lower $\mathrm{K}_{\mathrm{i}, \mathrm{BM}, \mathrm{QND}}$ values of 0.027 and $0.27 \mu \mathrm{M}$ (Figs. 5(A)). In the case of verapamil inhibition, the simulated digoxin concentrations overlapped the observed concentrations in the presence of verapamil, except at the lowest $\mathrm{K}_{\mathrm{i}, \mathrm{BM}, \mathrm{VRP}}(0.055 \mu \mathrm{M})$

(Figs. 5(B)). 
Since the steady state of digoxin was not achieved at the reported perfusion time of $120 \mathrm{~min}$, simulations of longer-term perfusions in the presence and absence of quinidine or verapamil were carried out (Supplemental Figures 2 (A)-(B)). For quinidine, the unbound syncytiotrophoblast concentration of quinidine at the steady state was estimated as $1.22 \mu \mathrm{g} / \mathrm{mL}$ which is higher than $\mathrm{K}_{\mathrm{i}, \mathrm{MDR} 1, \mathrm{MVM}, \mathrm{QND}}$ and $\mathrm{K}_{\mathrm{i}, \mathrm{BM}, \mathrm{QND}} \mathrm{S}$ (Supplemental Figure $2(\mathbf{C})$ ). Indeed, the simulation profiles in the case of longer-term perfusion (5,000 min, Supplemental Figure 2 (A)) were different in the presence and absence of quinidine. The co-administration of quinidine decreased the fetal transfer of digoxin if the efflux transporter at the BM showed higher affinity $\left(\mathrm{K}_{\mathrm{i}, \mathrm{BM}, \mathrm{QND}} \mathrm{S} 0.027\right.$ and $\left.0.27 \mu \mathrm{M}\right)$, but increased the transfer if the efflux transporter at BM was insensitive or had the lowest affinity $\left(\mathrm{K}_{\mathrm{i}, \mathrm{BM}, \mathrm{QND}} 2.7 \mu \mathrm{M}\right)$. For verapamil, the unbound syncytiotrophoblast concentration of verapamil was constant at $41.2 \mathrm{ng} / \mathrm{mL}$ due to assumption of the static model and was lower than $\mathrm{K}_{\mathrm{i}, \mathrm{MDR} 1 \text {,MVM,VRP }}$ or $\mathrm{K}_{\mathrm{i}, \mathrm{BM}, \mathrm{VRPS}}$ (Supplemental Figure 2 (D)). Therefore, the simulation profiles for long-term perfusion showed little difference between the presence and absence of verapamil, except for the case that the efflux transporter at BM showed the highest affinity $\left(\mathrm{K}_{\mathrm{i}, \mathrm{BM}, \mathrm{VRP}} 0.055 \mu \mathrm{M}\right)($ Supplemental Figure 2 (B)).

\section{Model Prediction for in vivo Human F:M ratio of Digoxin}

In the ex vivo experiment (Derewlany et al., 1991), a lower albumin concentration (Table 1) than 
that in vivo was used, and the perfusion of digoxin was terminated at $180 \mathrm{~min}$. When the digoxin $\mathrm{C}_{\mathrm{ma}}$ and $\mathrm{C}_{\mathrm{uv}}$ were simulated with a higher albumin concentration reflecting the in vivo value $\left(\mathrm{f}_{\mathrm{u}, \mathrm{med}}=0.67\right.$ for mother and fetus) and longer-term perfusion, the time to achieve the steady state $\left(t_{\mathrm{ss}}\right)$ was approximately 1,500 min (Fig. 6). The F:M ratio at the steady state in the in vivo condition was calculated as approximately 0.66 , which is consistent with previously reported in vivo F:M ratios (mean [95\% confidence interval (CI)]: 0.77 [0.64-0.91]) (Fig. 7).

\section{Estimation of in vivo F:M ratio for DDIs between Digoxin and MDR1 Inhibitors}

As described above, co-administration with quinidine might decrease the fetal transfer of digoxin based on the results of ex vivo DDI simulations for long-term perfusion. In clinical settings, the increase of maternal digoxin exposure due to inhibition of MDR1 in small intestine and kidney should also be considered. It is reported that quinidine increases the digoxin exposure, i.e., $\mathrm{C}_{\max }$ and the area under the plasma concentration-time curve (AUC), by approximately 1.8 -fold, while verapamil increases it by approximately 1.4 -fold after digoxin oral administration with quinidine or verapamil, respectively (Pedersen et al., 1983; Rodin et al., 1988). Therefore, the maternal and fetal exposures to digoxin were simulated using the reported clinical $\mathrm{C}_{\max }$ of digoxin after co-administration with quinidine or verapamil as an initial $\mathrm{C}_{\mathrm{mr}}$ (Pedersen et al., 1983; Rodin et al., 1988) by the developed transplacental PK model, and the results were compared with the simulation 
using data in the absence of the MDR1 inhibitor (Supplemental Table 5). In parallel, the developed transplacental PK model for quinidine was used with its reported clinical $\mathrm{C}_{\max }$ as an initial $\mathrm{C}_{\mathrm{mr}}$ for the simulation of the unbound syncytiotrophoblast concentration of quinidine. For verapamil, the unbound syncytiotrophoblast concentration was calculated from its reported clinical $\mathrm{C}_{\max }$ with the assumption that the verapamil concentration was maintained at $\mathrm{C}_{\max }$ throughout the perfusion.

The observed digoxin concentrations in ex vivo DDI perfusion experiments with quinidine were appropriately accounted for by the two simulations in which quinidine inhibited the efflux transporter at BM with $\mathrm{K}_{\mathrm{i}, \mathrm{BM}, \mathrm{QND}} \mathrm{S} 0.027$ and $0.27 \mu \mathrm{M}$ and also inhibited MDR1 at the MVM with $\mathrm{K}_{\mathrm{i}, \mathrm{MDR} 1, \mathrm{MVM}, \mathrm{QND}} 0.27 \mu \mathrm{M}$ (Fig. 5(A)). Therefore, the maternal and fetal digoxin concentration profiles were simulated by the developed model by using these $\mathrm{K}_{\mathrm{i}}$ values and the digoxin $\mathrm{C}_{\max }$ obtained from a clinical DDI study with quinidine (Pedersen et al., 1983) (Fig. 8 (A)). The steady-state digoxin concentration in the fetus after co-administration of quinidine was comparable to that in the absence of quinidine (red dashed line) in the simulation with $\mathrm{K}_{\mathrm{i}, \mathrm{BM} \text {,QND }} 0.027 \mu \mathrm{M}$ (green dashed line), but 1.6-fold higher in the simulation with $\mathrm{K}_{\mathrm{i}, \mathrm{BM}, \mathrm{QND}} 0.27 \mu \mathrm{M}$ (blue dashed line). Those in the mother (solid lines) were increased in both simulations, because of the higher digoxin concentrations resulting from inhibition of both MDR1 in maternal organs other than placenta and the efflux transporter at the $\mathrm{BM}$ in placenta, even with a decrease in $\mathrm{PS}_{\mathrm{MVM} \text {,act,eff }}$ due to MDR1 
inhibition at the MVM. At the steady state, the unbound quinidine concentration in syncytiotrophoblast was estimated as $0.20 \mu \mathrm{g} / \mathrm{mL}(=0.62 \mu \mathrm{M})$, which is higher than $\mathrm{K}_{\mathrm{i}, \mathrm{MDR} 1, \mathrm{MVM} \text {, QND }}$ $(0.27 \mu \mathrm{M})$ and $\mathrm{K}_{\mathrm{i}, \mathrm{BM}, \mathrm{QND}} \mathrm{S}(0.027$ and $0.27 \mu \mathrm{M})$ (Fig. $\left.8(\mathbf{C})\right)$. The F:M ratios of digoxin were estimated as 0.27 and 0.58 in the simulations with $\mathrm{K}_{\mathrm{i}, \mathrm{BM}, \mathrm{QND}} 0.027$ and $0.27 \mu \mathrm{M}$, respectively, while that in the absence of quinidine was 0.66 .

For verapamil, the three simulations in which the efflux transporter at the BM was sensitive to verapamil with $\mathrm{K}_{\mathrm{i}, \mathrm{BM}, \mathrm{VRP}} 0.55$ and $5.5 \mu \mathrm{M}$ or was insensitive, while verapamil inhibits MDR1 at the MVM with $\mathrm{K}_{\mathrm{i}, \mathrm{MDR} 1, \mathrm{MVM}, \mathrm{VRP}} 0.55 \mu \mathrm{M}$, adequately accounted for the observed digoxin concentrations in the ex vivo DDI perfusion experiments (Fig. 5(B)). With these $\mathrm{K}_{\mathrm{i}}$ values and the digoxin $\mathrm{C}_{\max }$ reported in a clinical DDI study with verapamil (Rodin et al., 1988), the maternal and fetal digoxin concentration profiles were simulated by the developed model (Fig. 8 (B)). As a result, the steady-state maternal and fetal digoxin concentrations in all simulations after co-administration of verapamil (blue, purple, and orange lines) were 1.4-1.5 fold higher than those in the absence of verapamil (red lines), which are almost the same as the increases in exposure observed in subjects who were not pregnant (Rodin et al., 1988). Therefore, the increments were mainly accounted for by MDR1 inhibition in maternal organs other than placenta due to the lower unbound verapamil concentration of $90.0 \mathrm{ng} / \mathrm{mL}(=0.20 \mu \mathrm{M})$, compared with $\mathrm{K}_{\mathrm{i}, \mathrm{MDR} 1, \mathrm{MVM}, \mathrm{VRP}}(0.55 \mu \mathrm{M})$ and $\mathrm{K}_{\mathrm{i}, \mathrm{BM}, \mathrm{VPR}} \mathrm{S}$ 
$(0.55$ and $5.5 \mu \mathrm{M})$ in syncytiotrophoblast (Fig. 8 (D)). The F:M ratios of digoxin after co-administration of verapamil were estimated to be $0.65-0.74$, which are almost the same as that in the absence of verapamil (0.66). 


\section{Discussion}

Data from ex vivo human placental perfusion were used here to predict fetal drug exposure in vivo. A previous systematic review (Hutson et al., 2011) stated that ex vivo F:M ratios were generally consistent with the in vivo F:M ratios, although there were 4 exceptions among 24 drugs, i.e., digoxin, metformin, glyburide, and oxcarbazepine. Those four drugs are substrates of active transporters, and digoxin is a typical MDR1 substrate (Tanigawara et al., 1992; Kullak-Ublick et al., 2001; Sata et al., 2005; Han et al., 2015; Nakamichi et al., 2013; Gedeon et al., 2006; Zhang et al., 2011). The F:M ratio of digoxin predicted by Hutson et al. (2011) was approximately 7-fold lower than the previously reported in vivo F:M ratio. In the present study, our developed human transplacental PK model of digoxin successfully predicted an F:M ratio (0.66) comparable with the in vivo value (0.77). When digoxin is used for fetal SVT, the concentration in the fetus should be adjusted to the therapeutic range with simultaneous adjustment of maternal exposure to avoid maternal digoxin toxicity. Thus, accurate prediction of the ratio is important for design of the dosing strategy.

Our analysis revealed that the reason for the discrepancy between in vivo and ex vivo F:M ratios of digoxin is that the estimated $\mathrm{t}_{\mathrm{ss}}$ is longer than the duration of perfusion in the previous ex vivo studies (Hutson et al., 2011). Recently, we reported a transplacental PK model of metformin (Kurosawa et 
al., 2020), another exception in Hutson's systematic review. The ex vivo F:M ratios of metformin from closed perfusion studies were 2- to 5-fold lower than the in vivo values, and this inconsistency was explained by the longer $\mathrm{t}_{\mathrm{ss}}$ than the perfusion time in the ex vivo experimental settings, as in the present case of digoxin. Both digoxin and metformin are low permeability compounds classified as biopharmaceutics classification system (BCS) class 3 (Cheng et al., 2004; Xia et al., 2013), which should have permeability-limited kinetics. Therefore, digoxin and metformin would have long $\mathrm{t}_{\mathrm{ss}}$ (1,500 min and 1,000 min, respectively) in ex vivo perfusion studies. In the previous metformin model and the present digoxin PK model, influx and efflux clearances were set in the MVM and BM, respectively, and successfully accounted for the permeability-limited kinetics.

In the previous transplacental PK model analysis of digoxin (Derewlany et al., 1991), a PK model consisting of maternal and fetoplacental compartments was applied to ex vivo human placental perfusion data to explain the digoxin concentration-time profile only on the maternal side. Since fetal concentrations were not used to build the model, the estimation of fetal exposure and comparison of ex vivo and in vivo data were not done. Moreover, since the syncytiotrophoblast compartment was not separated from the fetal compartment and transportation between placenta and fetus was not considered, it is difficult to simulate transporter-mediated DDI at the unbound drug concentration in syncytiotrophoblasts. On the other hand, our PK model shown in Fig. 2(A) 
successfully predicted the DDIs in human placenta by taking account of the possibility that the efflux transporter at the BM is inhibited by MDR1 inhibitors.

The present model incorporates four transporter-mediated clearances in the transplacental transfer of digoxin. When we compared the model-estimated active transport clearances of digoxin with the passive diffusion clearances obtained from parallel artificial membrane permeation assay (PAMPA), the active transport clearances were 2 to 7 times larger than the PAMPA clearances (Table 1). Moreover, when the model fitting was performed with only four passive clearances, one solely passive and three hybrid clearances (passive + active clearances), two solely passive and two hybrid clearances, or three solely passive and one hybrid clearances, convergence failed in all cases (data not shown). Furthermore, sensitivity analyses for the four transporters were performed to investigate the influences of changes in the activities (Supplemental Figure 3). As a result, the digoxin concentration profiles were sensitively shifted by each change in clearance, and the robustness of the model with the four estimated clearances were confirmed. These results clearly indicate that transporters are involved in the influx and efflux transport at the MVM and BM.

Among transporters expressed at the MVM of human placental syncytiotrophoblasts, the efflux transport of digoxin from the syncytiotrophoblasts to the maternal intervillous space by MDR1 has 
been functionally confirmed, since the uptake of digoxin into human placental MVM vesicles was decreased in the presence of MDR1 inhibitors such as verapamil, progesterone and cyclosporine A (Ushigome et al., 2003). Organic anion transporting polypeptide (OATP) $1 \mathrm{~B} 3$ has been reported to transport digoxin in the human placenta (Tupova et al., 2020; Kullak-Ublick et al., 2001), but this remains controversial (Kimoto et al., 2011; Taub et al., 2011). Further investigation is necessary to evaluate digoxin transport by OATP1B3 in human placenta. At the BM, MDR3 and MDR1 at the cytotrophoblast adjacent to the syncytiotrophoblast could transport their substrates from syncytiotrophoblasts to fetus (Evseenko et al., 2006; Lye et al., 2013; Kliman et al., 2018; Ontsouka et al., 2021). Digoxin is a substrate of MDR3 (Smith et al., 2000) and MDR1, which are inhibited by quinidine and verapamil (Schlemmer and Sirotnak, 1994; Aleo et al., 2017). Therefore, we assumed that the efflux transporter at BM could be sensitive to the inhibitors.

In the ex vivo human placental perfusion study of DDI (Holcberg et al., 2003), no inhibition by quinidine or verapamil was observed. Our simulations imply that the efflux transporter at the BM, as well as MDR1 at the MVM, is sensitive to the inhibitors. However, it should be noted that simulation profiles of digoxin concentration in the absence of inhibitor (red lines in Figs. 5(A)-(B)) were also rather similar to the observed digoxin concentrations in the presence of inhibitor. So, we cannot yet completely rule out the possibility that the efflux transporters at the MVM and BM are 
both insensitive to quinidine and verapamil. Further investigations are necessary to clarify the functional role of MDR1 and/or MDR3 at the fetal side of the placenta.

When digoxin is co-administered with MDR1 inhibitors, the increase of maternal digoxin exposure due to inhibition of MDR1-mediated secretion in small intestine and kidney should be considered (Fenner et al., 2009). When the maternal concentrations of digoxin were increased 1.8- and 1.4-fold by quinidine and verapamil in our ex vivo perfusion models, respectively, the simulated fetal digoxin concentrations were similarly increased by verapamil, though this was not the case for quinidine (Figs. 8(A)-(B)). The unbound syncytiotrophoblast quinidine concentration was estimated to be higher than the values of $\mathrm{K}_{\mathrm{i}, \mathrm{MDR} 1, \mathrm{MVM}, \mathrm{QND}}$ and $\mathrm{K}_{\mathrm{i}, \mathrm{BM}, \mathrm{QND}}$ and should inhibit both MDR1 at MVM and the efflux transporter at the BM. The stronger inhibition of the efflux transporter at the BM results in lower fetal digoxin concentrations. On the other hand, for verapamil, the increments in fetal exposure were accounted for by the inhibition of MDR1 in the maternal intestine and kidney, but not in the placenta because of the lower unbound syncytiotrophoblast concentration of verapamil than $\mathrm{K}_{\mathrm{i}, \mathrm{MDR} 1, \mathrm{MVM}, \mathrm{VRP}}$ and $\mathrm{K}_{\mathrm{i}, \mathrm{BM}, \mathrm{VRP}}$. Thus, because of an increase in digoxin concentration in the mother even if the increase in fetal digoxin concentration is similar to or less than that of maternal concentration, therapeutic monitoring of digoxin should be considered to predict fetal exposure when these MDR1 inhibitors are co-administered with digoxin in vivo. 
In this study, we also constructed the first human transplacental PK model of quinidine with transporter-mediated clearances. Transporters involved in the transplacental transfer of quinidine have not yet been clarified. However, since quinidine is a substrate of MDR1 (Patil et al., 2011), which is located at the MVM, MDR1 is likely to serve as the MVM efflux transporter. As for other transporters, when four passive diffusions or those with transporter clearances were tested, only the model fitting with MDR1 on MVM and an unknown efflux transporter on BM with four passive diffusions converged (data not shown). This model made it possible to estimate the MDR1-inhibitory effect of quinidine on digoxin transplacental transfer. Considering that quinidine is a substrate of OCT3 (Hasannejad et al., 2004), which is expressed at the BM (Kekuda et al., 1998), OCT3 may contribute to the transportation of quinidine in the placenta.

For the successful construction of the transplacental PK model from ex vivo perfusion studies, digoxin concentrations in non-perfused tissue as well as maternal artery, umbilical vein, perfused tissue, and the weight of perfused tissue are required. The volumes of maternal intervillous, syncytiotrophoblast and fetal capillaries can be calculated from reported values (Supplemental Text). On the other hand, it is difficult to measure the non-perfused tissue volume accurately because of unexpected spontaneous blood clotting and the vague boundary with decidual septa. Therefore, 
the drug concentration in non-perfused tissue has rarely been measured, though it is important for developing the transplacental PK model to estimate the volume of non-perfused tissue incorporated in the model.

In conclusion, the developed human transplacental PK model of digoxin with four different transporter-mediated clearances well predicted the in vivo fetal exposure. This model should be useful to predict in vivo fetal exposure and also DDI in the human placenta. 


\section{Acknowledgements}

The authors would like to thank Drs. Mahmoud S. Ahmed and Tatiana Nanovskaya for allowing us

to visit their laboratory to observe their ex vivo human placental perfusion study.

\section{Author Contributions}

Participated in research design: Kurosawa, Chiba, Noguchi, Nishimura, Tomi.

Performed research: Kurosawa, Chiba, Tomi.

Contributed new reagents or analytic tools: Kurosawa, Chiba, Tomi.

Performed data analysis: Kurosawa, Chiba.

Wrote or contributed to the writing of the manuscript: Kurosawa, Chiba, Noguchi, Nishimura, Tomi. 


\section{References}

Aleo MD, Shah F, He K, Bonin PD, and Rodrigues AD (2017) Evaluating the role of multidrug resistance protein 3 (MDR3) inhibition in predicting drug-induced liver injury using 125 pharmaceuticals. Chem Res Toxicol 30:1219-1229.

Beal SL, and Sheiner LB. NONMEM user's guide, part I. San Francisco: University of California at San Francisco; 1992.

Beller GA, Smith TW, Abelmann WH, Haber E, and Hood WB (1971) Digitalis Intoxication. N Engl J Med 284:989-997.

Belpaire FM, Wynant P, Van Trappen P, Dhont M, Verstraete A, and Bogaert MG (1995) Protein binding of propranolol and verapamil enantiomers in maternal and foetal serum. Br J Clin Pharmacol 39:190-193.

Bieche I, Narjoz C, Asselah T, Vacher S, Marcellin P, Lidereau R, Beaune P, and Waziers I De (2007) Reverse transcriptase-PCR quantification of mRNA levels from cytochrome (CYP)1, CYP2 and CYP3 families in 22 different human tissues. Pharmacogenet Genomics 17:731742.

Ceccaldi P-F, Gavard L, Mandelbrot L, Rey E, Farinotti R, Treluyer J-M, and Gil S (2009)

Functional role of P-glycoprotein and binding protein effect on the placental transfer of 
lopinavir/ritonavir in the ex vivo human perfusion model. Obstet Gynecol Int 2009:1-6.

Ceckova-Novotna M, Pavek P, and Staud F (2006) P-glycoprotein in the placenta: Expression, localization, regulation and function. Reproductive Toxicology 22:400-410.

Chan V, Tse TF, and Wong V (1978) Transfer of digoxin across the placenta and into breast milk. Br J Obstet Gynaecol 85:605-609.

Cheng CL, Yu LX, Lee HL, Yang CY, Lue CS, and Chou CH (2004) Biowaiver extension potential to BCS Class III high solubility-low permeability drugs: Bridging evidence for metformin immediate-release tablet. Eur J Pharm Sci 22:297-304.

Derewlany LO, Leeder JS, Kumar R, Radde IC, Knie B, and Koren G (1991) The transport of digoxin across the perfused human placental lobule. J Pharmacol Exp Ther 256:1107-1111.

DerSimonian R, and Laird N (1986) Meta-analysis in clinical trials. Control Clin Trials 7:177-188.

Evseenko DA, Paxton JW, and Keelan JA (2006) ABC drug transporter expression and functional activity in trophoblast-like cell lines and differentiating primary trophoblast. Am J Physiol Regul Integr Comp Physiol 290:1357-1365.

Evseenko DA, Paxton JW, and Keelan JA (2007) Independent regulation of apical and basolateral drug transporter expression and function in placental trophoblasts by cytokines, steroids, and growth factors. Drug Metab Dispos 35:595-601. 
Eyal S, Chung FS, Muzi M, Link JM, Mankoff DA, Kaddoumi A, O’Sullivan F, Hebert MF, and Unadkat JD (2009) Simultaneous PET imaging of P-glycoprotein inhibition in multiple tissues in the pregnant nonhuman primate. $\mathrm{J} \mathrm{Nucl} \mathrm{Med} \mathrm{50:798-806.}$

Fenner KS, Troutman MD, Kempshall S, Cook JA, Ware JA, Smith DA, and Lee CA (2009) Drug-drug interactions mediated through P-glycoprotein: Clinical relevance and in vitro-in vivo correlation using digoxin as a probe drug. Clin Pharmacol Ther 85:173-181.

Gedeon C, Behravan J, Koren G, and Piquette-Miller M (2006) Transport of glyburide by placental ABC transporters: Implications in fetal drug exposure. Placenta 27:1096-1102.

Grafmüller S, Manser P, Krug HF, Wick P, and von Mandach U (2013) Determination of the transport rate of xenobiotics and nanomaterials across the placenta using the ex vivo human placental perfusion model. $J$ Vis Exp 1-7.

Grigsby P (2016) Animal models to study placental development and function throughout normal and dysfunctional human pregnancy. Semin Reprod Med 34:011-016.

Gundalli SM, Kolekar R, Sunita VN, and Nandurkar V (2015) Placenta in eclampsia and preeclampsia. IOSR J Dental Med Sci, 14: 46-51.

Hakkola J, Pasanen M, Hukkanen J, Pelkonen O, Mäenpää J, Edwards RJ, Boobis AR, and Raunio H (1996) Expression of xenobiotic-metabolizing cytochrome P450 forms in human full-term 
placenta. Biochem Pharmacol 51:403-411.

Han T, Proctor WR, Costales CL, Cai H, Everett RS, and Thakker DR (2015) Four cation-selective transporters contribute to apical uptake and accumulation of metformin in Caco-2 cell monolayers. J Pharmacol Exp Ther 352:519-528.

Hasannejad H, Takeda M, Narikawa S, Huang XL, Enomoto A, Taki K, Niwa T, Jung SH, Onozato ML, Tojo A, and Endou H (2004) Human organic cation transporter 3 mediates the transport of antiarrhythmic drugs. Eur J Pharmacol 499:45-51.

Hebert MF, Easterling TR, Kirby B, Carr DB, Buchanan ML, Rutherford T, Thummel KE, Fishbein DP, and Unadkat JD (2008) Effects of pregnancy on CYP3A and P-glycoprotein activities as measured by disposition of midazolam and digoxin: A university of Washington specialized center of research study. Clin Pharmacol Ther 84:248-253.

Holcberg G, Sapir O, Tsadkin M, Huleihel M, Lazer S, Katz M, Mazor M, and Ben-Zvi Z (2003) Lack of interaction of digoxin and P-glycoprotein inhibitors, quinidine and verapamil in human placenta in vitro. Eur J Obstet Gynecol Reprod Biol 109:133-137.

Hubert U, Genz T, and Reinhardt D (1985) Comparison of the serum protein binding of digoxin in premature and mature newborns, infants and adults. Biol Res Pregnancy Perinatol 6:118-20.

Hutson JR, Garcia-Bournissen F, Davis A, and Koren G (2011) The human placental perfusion 
model: A systematic review and development of a model to predict in vivo transfer of therapeutic drugs. Clin Pharmacol Ther 90: 67-76.

Kekuda R, Prasad PD, Wu X, Wang H, Fei Y-J, Leibach FH, and Ganapathy V (1998) Cloning and functional characterization of a potential-sensitive, polyspecific organic cation transporter (OCT3) most abundantly expressed in placenta. J Biol Chem 273:15971-15979.

Kimoto E, Chupka J, Xiao Y, Bi YA, and Duignan DB (2011) Characterization of digoxin uptake in sandwich-cultured human hepatocytes. Drug Metab Dispos 39:47-53.

Kliman HJ, Quaratella SB, Setaro AC, Siegman EC, Subha ZT, Tal R, Milano KM, and Steck TL (2018) Pathway of maternal serotonin to the human embryo and fetus. Endocrinology 159:1609-1629.

Kullak-Ublick GA, Ismair MG, Stieger B, Landmann L, Huber R, Pizzagalli F, Fattinger K, Meier PJ, and Hagenbuch B (2001) Organic anion-transporting polypeptide B (OATP-B) and its functional comparison with three other OATPs of human liver. Gastroenterology 120:525533.

Kurosawa K, Chiba K, Noguchi S, Nishimura T, and Tomi M (2020) Development of a pharmacokinetic model of transplacental transfer of metformin to predict in vivo fetal exposure. Drug Metab Dispos 48:1293-1302. 
Lye P, Bloise E, Dunk C, Javam M, Gibb W, Lye SJ, and Matthews SG (2013) Effect of oxygen on multidrug resistance in the first trimester human placenta. Placenta 34:817-823.

Malhamé I, Gandhi C, Tarabulsi G, Esposito M, Lombardi K, Chu A, and Chen KK (2019) Maternal monitoring and safety considerations during antiarrhythmic treatment for fetal supraventricular tachycardia. Obstet Med 12:66-75.

Martin-Suarez A, Sanchez-Hernandez JG, Medina-Barajas F, Pérez-Blanco JS, Lanao JM,

Garcia-Cuenllas Alvarez L, and Calvo MV (2017) Pharmacokinetics and dosing requirements of digoxin in pregnant women treated for fetal supraventricular tachycardia. Expert Rev Clin Pharmacol 10:911-917.

Mathiesen L, Mose T, Mørck TJ, Nielsen JKS, Nielsen LK, Maroun LL, Dziegiel MH, Larsen LG, and Knudsen LE (2010) Quality assessment of a placental perfusion protocol. Reprod Toxicol 30:138-146.

Mayhew TM, Jenkins H, Todd B, and Clifton VL (2008) Maternal asthma and placental morphometry: Effects of severity, treatment and fetal sex. Placenta 29:366-373.

Mihaly G, Ching M, Klejn M, Paull J, and Smallwood R (1987) Differences in the binding of quinine and quinidine to plasma proteins. Br J Clin Pharmacol 24:769-774.

Miyoshi T, Maeno Y, Hamasaki T, Inamura N, Yasukochi S, Kawataki M, Horigome H, Yoda H, 
Taketazu M, Nii M, Hagiwara A, Kato H, Shimizu W, Shiraishi I, Sakaguchi H, Ueda K,

Katsuragi S, Yamamoto H, Sago H, and Ikeda T (2019) Antenatal therapy for fetal

supraventricular tachyarrhythmias: Multicenter trial. J Am Coll Cardiol 74:874-885.

Mölsä M, Heikkinen T, Hakkola J, Hakala K, Wallerman O, Wadelius M, Wadelius C, and Laine K

(2005) Functional role of P-glycoprotein in the human blood-placental barrier. Clin Pharmacol

Ther 78:123-131.

Myren M, Mose T, Mathiesen L, and Knudsen LE (2007) The human placenta - An alternative for studying foetal exposure. Toxicol Vitr 21:1332-1340.

Nagashima M, Asai T, Suzuki C, Matsushima M, and Ogawa A (1986) Intrauterine supraventricular tachyarrhythmias and transplacental digitalisation. Arch Dis Child 61:996-1000.

Nakamichi N, Shima H, Asano S, Ishimoto T, Sugiura T, Matsubara K, Kusuhara H, Sugiyama Y, Sai Y, Miyamoto KI, Tsuji A, and Kato Y (2013) Involvement of carnitine/organic cation transporter OCTN1/SLC22A4 in gastrointestinal absorption of metformin. J Pharm Sci 102:3407-3417.

Nanovskaya T, Nekhayeva I, Karunaratne N, Audus K, Hankins GDV, and Ahmed MS (2005) Role of P-glycoprotein in transplacental transfer of methadone. Biochem Pharmacol 69:1869-1878.

Nekhayeva IA, Nanovskaya TN, Hankins GDV, and Ahmed MS (2006) Role of human placental 
efflux transporter P-glycoprotein in the transfer of buprenorphine, levo- $\alpha$-acetylmethadol, and paclitaxel. Am J Perinatol 23:423-430.

Nielsen TL, Rasmussen BB, Flinois JP, Beaune P, and Brøsen K (1999) In vitro metabolism of quinidine: The (3S)-3-hydroxylation of quinidine is a specific marker reaction for cytochrome P-4503A4 activity in human liver microsomes. J Pharmacol Exp Ther 289:31-37.

Ontsouka E, Epstein A, Kallol S, Zaugg J, Baumann M, Schneider H, and Albrecht C (2021) Placental expression of bile acid transporters in intrahepatic cholestasis of pregnancy. Int J Mol Sci 22:10434.

Panigel M, James AE, Siegel M, and Donner MW (1975) Radionuclide and angiographic studies of placental circulation in man and rhesus monkey. Eur J Obstet Gynecol Reprod Biol 5:251-262.

Patil AG, D'Souza R, Dixit N, and Damre A (2011) Validation of quinidine as a probe substrate for the in vitro P-gp inhibition assay in Caco-2 cell monolayer. Eur J Drug Metab Pharmacokinet 36:115-119.Pedersen KE, Christiansen BD, Klitgaard NA, and Nielsen-Kudsk F (1983) Effect of quinidine on digoxin bioavailability. Eur J Clin Pharmacol 24:41-47.

Ragab AR, Al-Mazroua MK, and Abdel-Rahman RH (2012) Clinical utility of serum digoxin level in cardiac patients for diagnosis of chronic digitalis toxicity. J Clin Toxicol 2: 1000150.

Rodgers T, Leahy D, and Rowland M (2005) Physiologically based pharmacokinetic modeling 1: 
Predicting the tissue distribution of moderate-to-strong bases. J Pharm Sci 94:1259-1276.

Rodin SM, Johnson BF, Wilson J, Ritchie P, and Johnson J (1988) Comparative effects of verapamil and isradipine on steady-state digoxin kinetics. Clin Pharmacol Ther 43:668-672.

Rogers MC, Willerson JT, Goldblatt A, and Smith TW (1972) Serum digoxin concentrations in the human fetus, neonate and infant. N Engl J Med 287:1010-1013.

Sata R, Ohtani H, Tsujimoto M, Murakami H, Koyabu N, Nakamura T, Uchiumi T, Kuwano M, Nagata H, Tsukimori K, Nakano H, and Sawada Y (2005) Functional analysis of organic cation transporter 3 expressed in human placenta. J Pharmacol Exp Ther 315:888-895.

Schlemmer SR, and Sirotnak FM (1994) Functional studies of P-glycoprotein in inside-out plasma membrane vesicles derived from murine erythroleukemia cells overexpressing MDR 3. J Biol Chem 269:31059-31066.

Smith AJ, Van Helvoort A, Van Meer G, Szabó K, Welker E, Szakács G, Váradi A, Sarkadi B, and Borst P (2000) MDR3 P-glycoprotein, a phosphatidylcholine translocase, transports several cytotoxic drugs and directly interacts with drags as judged by interference with nucleotide trapping. J Biol Chem 275:23530-23539.

Strzelecka I, Respondek-Liberska M, Słodki M, Zych-Krekora K, and Cuneo B (2017) Review paper. Transplacental digoxin treatment in prenatal cardiac problems in singleton pregnancies - meta 
analysis (based on literature: 1992-2015). Prenat Cardiol 6:67-74.

Sudhakaran S, Rayner CR, Li J, Kong DCM, Gude NM, and Nation RL (2008) Inhibition of placental P-glycoprotein: Impact on indinavir transfer to the foetus. Br J Clin Pharmacol 65:667-673.

Tanigawara Y, Okamura N, Hirai M, Yasuhara M, Ueda K, Kioka N, Komano T, and Hori R (1992) Transport of digoxin by human P-glycoprotein expressed in a porcine kidney epithelial cell line (LLC-PK1). J Pharmacol Exp Ther 263:840-845.

Tantivatana P, and Wright SE (1958) Estimation of digoxin and digitoxin in digitalis lanata. J Pharm Pharmacol 10:189-193.

Taub ME, Mease K, Sane RS, Watson CA, Chen L, Ellens H, Hirakawa B, Reyner EL, Jani M, and Lee CA (2011) Digoxin is not a substrate for organic anion-transporting polypeptide transporters OATP1A2, OATP1B1, OATP1B3, and OATP2B1 but is a substrate for a sodium-dependent transporter expressed in HEK293 cells. Drug Metab Dispos 39:2093-2102.

Tracy TS, Korzekwa KR, Gonzalez FJ, and Wainer IW (1999) Cytochrome P450 isoforms involved in metabolism of the enantiomers of verapamil and norverapamil. Br J Clin Pharmacol 47:545-552.

Troutman MD, and Thakker DR (2003) Novel experimental parameters to quantify the modulation 
of absorptive and secretory transport of compounds by P-glycoprotein in cell culture models of intestinal epithelium. Pharm Res 20:1210-1224.

Tsadkin-tamir M (2005) Transplacental transfer of the drugs: transplacental transfer of p-glycoprotein substrates and interaction with p-glycoprotein inhibitors. Accessed via https://primo.bgu.ac.il/permalink/f/14tjq6c/972BGU_ALMA51118865170004361 on $1 / 3 / 2021$.

Tupova L, Hirschmugl B, Sucha S, Pilarova V, Székely V, Bakos É, Novakova L, Özvegy-Laczka C, Wadsack C, and Ceckova M (2020) Interplay of drug transporters P-glycoprotein (MDR1), MRP1, OATP1A2 and OATP1B3 in passage of maraviroc across human placenta. Biomed Pharmacother 129:110506.

Ushigome F, Koyabu N, Satoh S, Tsukimori K, Nakano H, Nakamura T, Uchiumi T, Kuwano M, Ohtani H, and Sawada Y (2003) Kinetic analysis of P-glycoprotein-mediated transport by using normal human placental brush-border membrane vesicles. Pharm Res 20:38-44.

Xia B, Heimbach T, Gollen R, Nanavati C, and He H (2013) A simplified PBPK modeling approach for prediction of pharmacokinetics of four primarily renally excreted and CYP3A metabolized compounds during pregnancy. AAPS J 15:1012-1024.

Zhang C, Zuo Z, Kwan P, and Baum L (2011) In vitro transport profile of carbamazepine, 
oxcarbazepine, eslicarbazepine acetate, and their active metabolites by human P-glycoprotein.

Epilepsia 52:1894-1904.

Zheng Y, Benet LZ, Okochi H, and Chen X (2015) Ph dependent but not p-gp dependent

bidirectional transport study of s-propranolol: The importance of passive diffusion. Pharm Res 32:2516-2526.

Zhou K, Hua Y, Zhu Q, Liu H, Yang S, Zhou R, and Guo N (2011) Transplacental digoxin therapy for fetal tachyarrhythmia with multiple evaluation systems. J Matern Neonatal Med 24:13781383.

Ziff OJ, Lane DA, Samra M, Griffith M, Kirchhof P, Lip GYH, Steeds RP, Townend J, and Kotecha D (2015) Safety and efficacy of digoxin: systematic review and meta-analysis of observational and controlled trial data. BMJ 351:h4451. 


\section{Footnotes}

We have no financial conflicts of interest, and no external funding was used in this research. 


\section{Figure Legends}

Fig. 1

Schematic illustration of the development of the digoxin transplacental PK model. i) Model construction. ii) Model verification. iii) Prediction of DDIs of digoxin and MDR1 inhibitors. iv)

Prediction of in vivo fetal exposure.

Fig. 2

The human transplacental PK model and perfusion experimental scheme. (A) The ex vivo human placental perfusion study used to develop the human transplacental PK model of digoxin and quinidine. A maternal reservoir was connected to maternal artery and vein cannulas and a fetal reservoir to umbilical vein and artery cannulas. The drugs were administered to the maternal reservoir and perfused in this closed system. Abbreviations are explained in Table 1. (B) The scheme of the ex vivo human placental perfusion study using a human placental lobule excised from human placenta (blue dashed square) containing perfused tissue connected to the fetal circulation and non-perfused tissue (shaded area).

Fig. 3 
Fitted digoxin concentration-time profiles in maternal artery (red solid line in A), maternal vein (blue solid line in A), umbilical vein (blue dashed line in A), umbilical artery (red dashed line in A), syncytiotrophoblast (black solid line in B), and non-perfused tissue (black dashed line in B) in a closed perfusion system (Derewlany et al., 1991). Open red circles, blue circles, blue triangles, and red triangles represent the mean reported concentrations of digoxin in maternal artery, maternal vein, umbilical vein and umbilical artery, respectively. The closed circles and triangles in B represent the mean reported concentration of digoxin in syncytiotrophoblast and non-perfused tissue, respectively. In the experiment, digoxin $(5.5 \mathrm{ng} / \mathrm{mL}$ at $0 \mathrm{~min})$ was added in the maternal reservoir.

Fig. 4

Simulated digoxin concentration-time profiles in maternal artery (black solid line) and umbilical vein (black dashed line) in a closed perfusion system (Holcberg et al., 2003). Closed circles and triangles represent the mean reported concentrations of digoxin in maternal artery and umbilical vein, respectively, without MDR1 inhibitor. In the experiment, digoxin $(6.07 \mu \mathrm{g} / \mathrm{mL})$ at 0 min was added to the maternal reservoir. Dotted lines represent the simulated concentration-time profiles from the sensitivity analysis of $\mathrm{V}_{\mathrm{ch}}$ (blue: $0 \mathrm{~mL}$, red: $50 \mathrm{~mL}$ ).

\section{Fig. 5}


Simulated digoxin concentration-time profiles in maternal artery (solid lines) and umbilical vein (dashed lines) after co-administration with quinidine (A) or verapamil (B) in a closed perfusion system (Holcberg et al., 2003). A: $\mathrm{K}_{\mathrm{i}, \mathrm{MDR} 1, \mathrm{MVM} \text {,QND }}$ was set as $0.27 \mu \mathrm{M}$ and $\mathrm{K}_{\mathrm{i}, \mathrm{BM} \text {,QND }}$ as 0.027 (green), 0.27 (blue), or $2.7 \mu \mathrm{M}$ (purple) with no inhibition by quinidine at the BM (orange). B: $\mathrm{K}_{\mathrm{i}, \mathrm{MDR} 1, \mathrm{MVM}, \mathrm{VRP}}$ was set as $0.55 \mu \mathrm{M}$ and $\mathrm{K}_{\mathrm{i}, \mathrm{BM}, \mathrm{VRP}}$ as 0.055 (green), 0.55 (blue), or $5.5 \mu \mathrm{M}$ (purple) with no inhibition by verapamil at the BM (orange). Black closed circles and triangles represent the reported mean concentrations of digoxin in maternal artery and umbilical vein. The red lines represent the simulated digoxin-concentration time profiles in maternal artery (solid) and umbilical vein (dashed) without MDR1 inhibitors. The lines in B, except for green lines, almost overlapped and are visually indistinguishable. Quinidine or verapamil was added to the maternal reservoir at $7.57 \mu \mathrm{g} / \mathrm{mL}$ or $250 \mathrm{ng} / \mathrm{mL}$, respectively. The medium without digoxin but including an MDR1 inhibitor was perfused for $45 \mathrm{~min}$ prior to start of digoxin perfusion. After the pre-perfusion period, digoxin $(6.07 \mathrm{ng} / \mathrm{mL}$ at $0 \mathrm{~min}$ in $\mathrm{A}, 5.22 \mathrm{ng} / \mathrm{mL}$ at $0 \mathrm{~min}$ in $\mathrm{B})$ was added to the maternal reservoir in the experiments. Digoxin concentrations in B were normalized by the initial maternal concentration observed in A $(6.07 \mathrm{ng} / \mathrm{mL})$.

Fig. 6 
The long-term simulation of digoxin concentration in maternal artery (black solid line) and umbilical vein (black dashed line). The simulation by the developed transplacental PK model of digoxin was performed under the experimental conditions of Derewlany et al. (1991), except for digoxin unbound fraction in mother and fetus of 0.67 (Hubert et al., 1985; Hebert et al., 2008) and the duration of perfusion of 5,000 min.

\section{Fig. 7}

In vivo $\mathrm{F}: \mathrm{M}$ ratios (mean $\pm 95 \% \mathrm{CI}$ ) of digoxin integrated from multiple sources (Rogers et al., 1972; Chan et al., 1978; Nagashima et al., 1986; Zhou et al., 2011) and the predicted and observed ex vivo F: M ratios (Derewlany et al., 1991; Holcberg et al., 2003). The criteria for literature selection to collect in vivo F:M ratios were as follows. i) Simultaneous blood sampling in full-term pregnant women was conducted in maternal venous and umbilical cord. ii) The F:M ratio with standard deviation or range could be obtained. The selected in vivo PK information of digoxin is shown in Supplemental Table 4. The predicted ex vivo F:M ratios $(\bullet)$ were derived from the steady state concentrations in simulations using the developed transplacental PK model of digoxin. The observed ex vivo F:M ratios at the end of the perfusion (mean values) ((๓): Derewlany et al., 1991; ( $\mathbf{\Delta}$ ): Holcberg et al., 2003) were calculated from the values obtained from the ex vivo perfusion studies as described in Materials and Methods. Open squares ( $\square$ ) represent the reported mean values 
of in vivo F:M ratio with the sample size (square size). The solid lines represent the $95 \%$ CIs. The mean ratios and 95\% CIs (fixed or random) were estimated using the Dersimonian and Laird method (Dersimonian and Laird, 1986).

Fig. 8

The long-term transplacental transfer simulations of digoxin for predicting inhibitory effects of placental MDR1 at the MVM and/or the efflux transporter at the BM by quinidine (A) and verapamil (B) on the basis that these inhibitors enhanced digoxin concentration in maternal reservoir after oral co-administration with digoxin by inhibiting MDR1 in maternal organs other than placenta. The digoxin concentration-time profiles in maternal artery (solid lines) and umbilical vein (dashed lines) were simulated in the presence of quinidine (green and blue lines in A) or verapamil (blue, purple and orange lines in $\mathrm{B}$ ) in a closed perfusion system (Holcberg et al., 2003). A: $\mathrm{K}_{\mathrm{i}, \mathrm{MDR} 1, \mathrm{MVM}, \mathrm{QND}}$ was set as $0.27 \mu \mathrm{M}$ and $\mathrm{K}_{\mathrm{i}, \mathrm{BM} \text {,QND }}$ as 0.027 (green) or $0.27 \mu \mathrm{M}$ (blue). B: $\mathrm{K}_{\mathrm{i}, \mathrm{MDR} 1, \mathrm{MVM}, \mathrm{VRP}}$ was set as 0.55 $\mu \mathrm{M}$ and $\mathrm{K}_{\mathrm{i}, \mathrm{BM}, \mathrm{VRP}}$ as 0.55 (blue), or $5.5 \mu \mathrm{M}$ (purple) with no inhibition by verapamil at the $\mathrm{BM}$ (orange). The red lines in A and B represent the simulated digoxin-concentration time profiles in maternal artery (solid) and umbilical vein (dashed) without the inhibitors. The lines in B, except for red lines, almost overlapped and are visually indistinguishable. The simulated quinidine and verapamil concentration-time profiles in syncytiotrophoblast (black solid) are presented in C and D, 
respectively. C: Green and blue represent $\mathrm{K}_{\mathrm{i}, \mathrm{BM}, \mathrm{QND}}$ values of 0.027 and $0.27 \mu \mathrm{M}$, respectively. $\mathrm{K}_{\mathrm{i}, \mathrm{MDR} 1, \mathrm{MVM}, \mathrm{QND}}$ overlapped with the blue line. D: Blue and purple lines represent $\mathrm{K}_{\mathrm{i}, \mathrm{BM} \text {,VRP }} 0.55$ and $5.5 \mu \mathrm{M}$, respectively. $\mathrm{K}_{\mathrm{i}, \mathrm{MDR} 1, \mathrm{MVM}, \mathrm{VRP}}$ overlapped with the blue line. The simulations by the developed transplacental PK model of digoxin followed Holcberg's ex vivo studies except for enhanced maternal digoxin concentrations in the case of co-administration with inhibitor (Pedersen et al., 1983; Rodin et al., 1988) and $\mathrm{f}_{\mathrm{u}, \mathrm{med}}$ in human plasma (Hubert et al., 1985; Mihaly et al., 1987; Belpaire et al., 1995; Hebert et al., 2008) (Supplemental Table 5). 
Tables.

Table 1. Parameters used and determined in the construction of digoxin human transplacental PK model

\section{Fixed or Fitted}

\section{Definition of (coefficient of}

Parameter

Reference

Comments

parameter

variation

[CV] \%)

Molecular

780.94

weight

Parameters of perfusion experimental settings

Unbound fraction

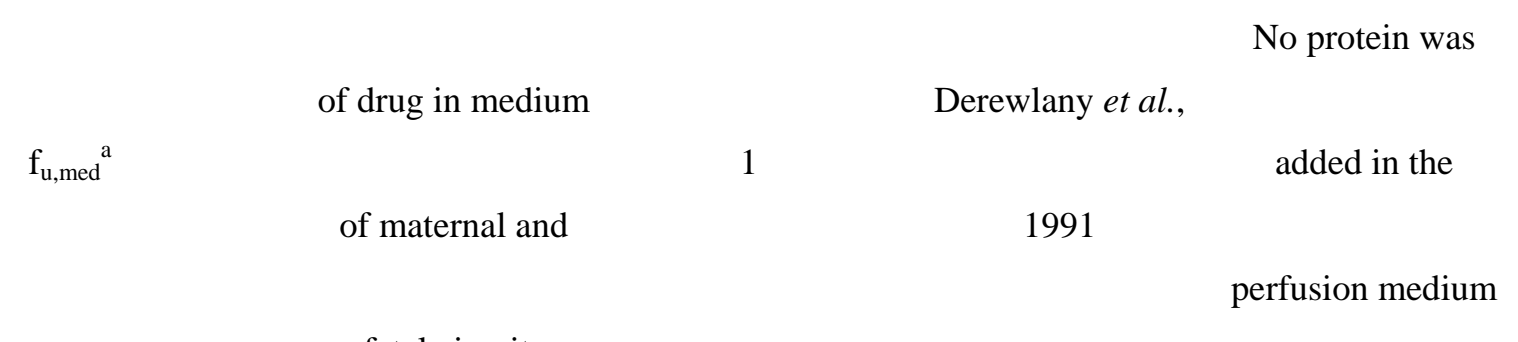

fetal circuits

Unbound fraction

Rodgers et al.,

$\begin{array}{lll}\mathrm{f}_{\mathrm{u}, \mathrm{t}}^{\mathrm{b}} & \text { of drug in } & 0.20\end{array}$

2005

syncytiotrophoblast 
Unbound fraction

of drug in

$f_{u, n p}$

non-perfused

placental tissue
Assumed to be the

0.20

same as $f_{u, t}$

$\mathrm{C}_{\mathrm{mr}}$ at start of

Total drug

digoxin

Derewlany et al.,

concentration in the

5.5

perfusion

1991

maternal reservoir

$(\mathrm{ng} / \mathrm{mL})$

Volume of maternal

$\mathrm{V}_{\mathrm{mr}}(\mathrm{mL})$

reservoir
Derewlany et al.,

246

1991

Volume of

Derewlany et al.,

$\mathrm{V}_{\mathrm{ma}}(\mathrm{mL})$

sampling port for

0.30

1991

maternal artery

Volume of

Derewlany et al.,

$\mathrm{V}_{\mathrm{mv}}(\mathrm{mL})$

sampling port for

0.30

1991

maternal vein 


\begin{tabular}{|c|c|c|c|}
\hline & Volume of & & Derewlany et al., \\
\hline \multirow[t]{3}{*}{$\mathrm{V}_{\mathrm{fa}}(\mathrm{mL})$} & sampling port for & 0.30 & \\
\hline & & & 1991 \\
\hline & umbilical artery & & \\
\hline
\end{tabular}

Volume of

Derewlany et al.,

$\begin{array}{lll}\mathrm{V}_{\mathrm{fv}}(\mathrm{mL}) \quad \text { sampling port for } & 0.30 & \\ & & 1991\end{array}$

umbilical vein

Volume of fetal

Derewlany et al.,

$\mathrm{V}_{\mathrm{fr}}(\mathrm{mL})$

135

reservoir

1991

Volume of the

$\mathrm{V}_{\mathrm{ch}}(\mathrm{mL}) \quad 17.5(0.005) \quad$ medium in the
maternal chamber

Perfusion flow rate

Derewlany et al.,

$\mathrm{Q}_{\mathrm{m}}(\mathrm{mL} / \mathrm{min})$

in the maternal side

1991

Perfusion flow rate

Derewlany et al.,

$\mathrm{Q}_{\mathrm{f}}(\mathrm{mL} / \mathrm{min})$

2.93

in the fetal side

1991

\section{Physiological parameters of human placental cotyledon}


Volume of fetal

$\mathrm{V}_{\mathrm{fc}}(\mathrm{mL})^{\mathrm{c}}$

$$
\mathrm{V}_{\mathrm{fc}}(\mathrm{mL})^{\mathrm{c}}
$$

capillaries
Mayhew et al.,

1.22

2008

\begin{tabular}{lccc}
\hline & Volume of maternal & & Mayhew et al., \\
$\mathrm{V}_{\mathrm{mi}}(\mathrm{mL})^{\mathrm{c}}$ & & 5.55 & 2008 \\
& intervillous space & & Mayhew et al., \\
& Volume of & & 2008 \\
$\mathrm{~V}_{\mathrm{t}}(\mathrm{mL})^{\mathrm{c}}$ & syncytiotrophoblast & & \\
& & & \\
\hline
\end{tabular}

\section{Transplacental PK parameters of digoxin}

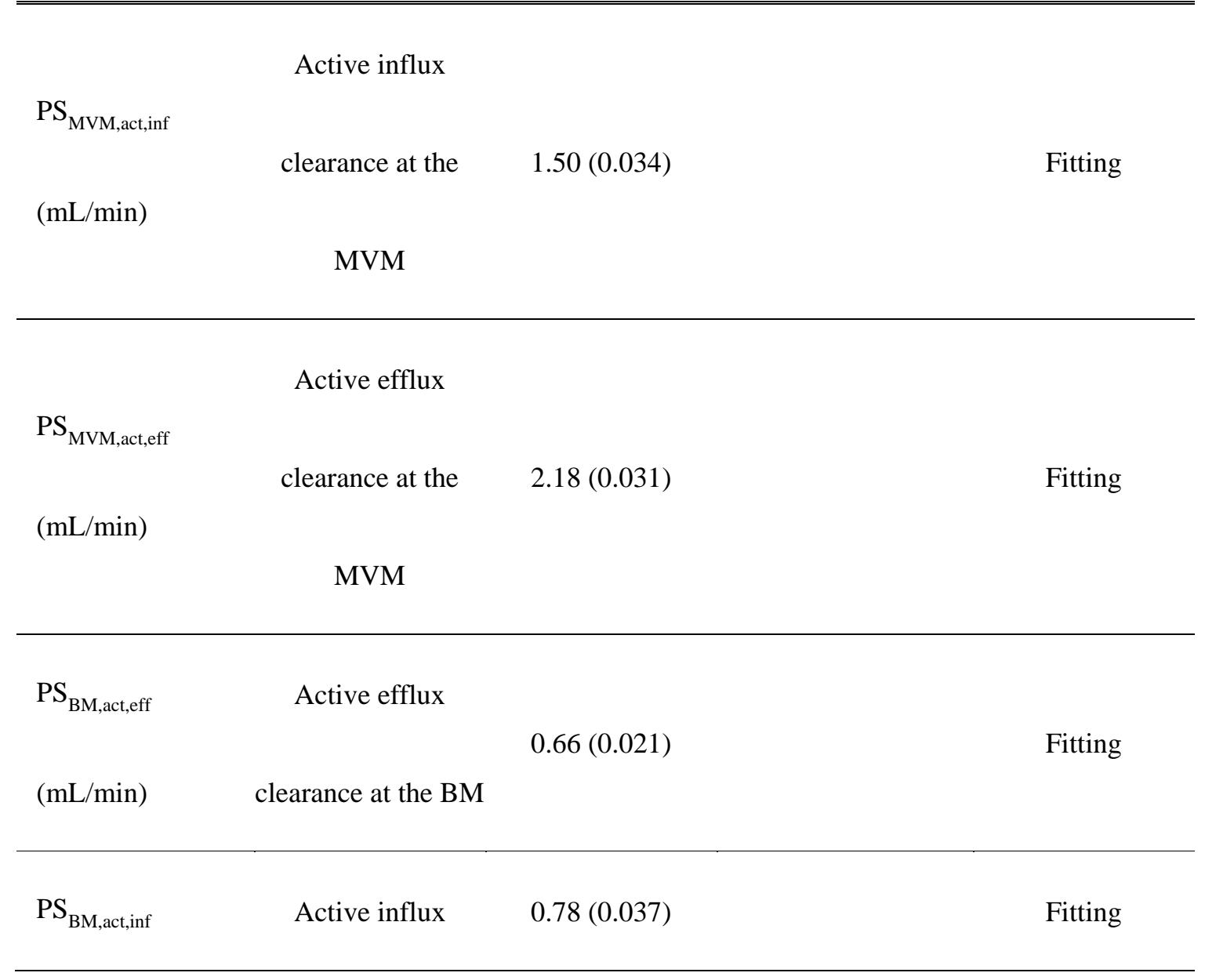


$(\mathrm{mL} / \mathrm{min}) \quad$ clearance at the BM

Intercompartmental

clearance between

$\mathrm{Q}_{\mathrm{np}}(\mathrm{ml} / \mathrm{min}) \quad$ maternal placenta $\quad 0.51(0.0015)$

Fitting

and non-perfused

placental tissue

Volume of

$\mathrm{V}_{\mathrm{np}}(\mathrm{ml})$

$49.6(0.0015)$

Fitting

non-perfused tissue

$\mathrm{PS}_{\text {MVM,diff }} \quad$ Passive clearance at

0.69 Zheng et al., 2015

(mL/min) the MVM

$\mathrm{PS}_{\mathrm{BM} \text {,diff }} \quad$ Passive clearance at

$0.12 \quad$ Zheng et al., 2015

(mL/min) the BM

a. Calculated using the following equation: $f u=\frac{1}{1+\frac{n \times P t}{K d}}$, n: number of binding sites, Pt: albumin concentration, $\mathrm{Kd}$ : dissociation constant.

b. The estimation method of $\mathrm{f}_{\mathrm{u}, \mathrm{t}}$ is described in the Supplemental text. 
c. The calculation method of perfused tissue volumes $\left(\mathrm{V}_{\mathrm{fc}}, \mathrm{V}_{\mathrm{mi}}\right.$ and $\left.\mathrm{V}_{\mathrm{t}}\right)$ is described in the

Supplemental text. $\mathrm{V}_{\mathrm{fc}}, \mathrm{V}_{\mathrm{mi}}$ and $\mathrm{V}_{\mathrm{t}}$ are expressed as volume of a single cotyledon unit in human placenta. 
i. Model construction of digoxin human transplacental PK by ex vivo human placental perfusion study in a closed system (Derewlany et al., 1991) (without MDR1 inhibitor)

ii. Model verification for digoxin human transplacental PK with external data

- Simulation for ex vivo perfusion study in a closed system (Holcberg et al., 2003) (without MDR1 inhibitor)

iii. DDI predictions of digoxin and MDR1 inhibitors (quinidine or verapamil) in ex vivo human placental perfusion studies

- Model development of quinidine human transplacental PK by ex vivo human placental perfusion study in a closed system (Tsadkin-Tamir., 2005)

- Simulations for ex vivo perfusion studies in a closed system (Holcberg et al., 2003) (digoxin with quinidine or verapamil)

iv. Prediction of fetal to maternal concentration $(F: M)$ ratio and comparison with reported in vivo values

- Simulations of $\mathrm{F}: \mathrm{M}$ ratios using developed human transplacental PK model of digoxin 
Figure 2.

A

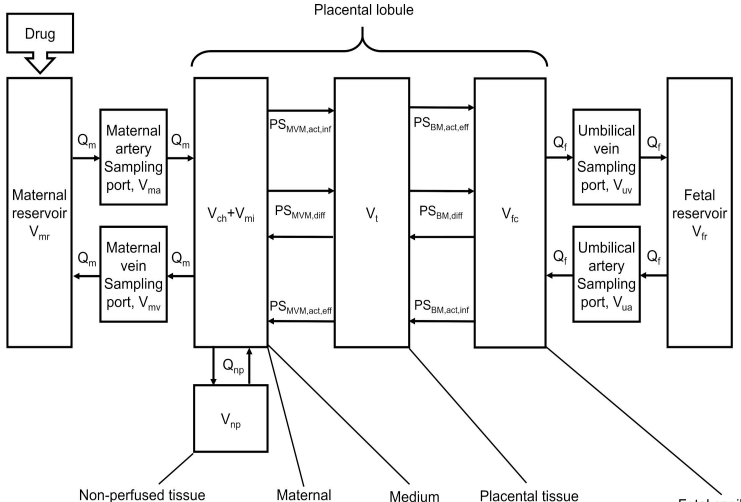

Non-perfused tissue

Maternal

Medium

Placental tissue

(Extra lobule)

intervillous space

(Syncytiotrophoblast)

B

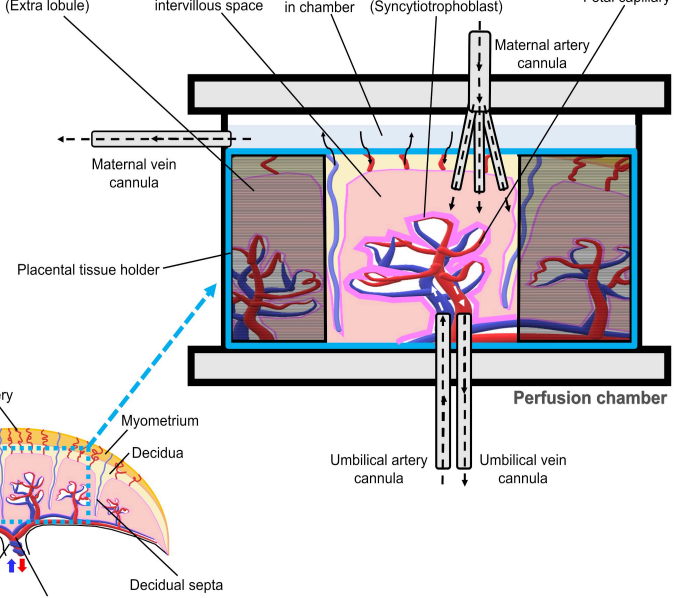

Maternal spiral artery

\section{Maternal vein}

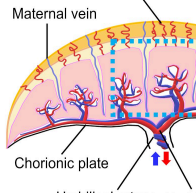

Umbilical artery
Decidual septa 
Figure 3.
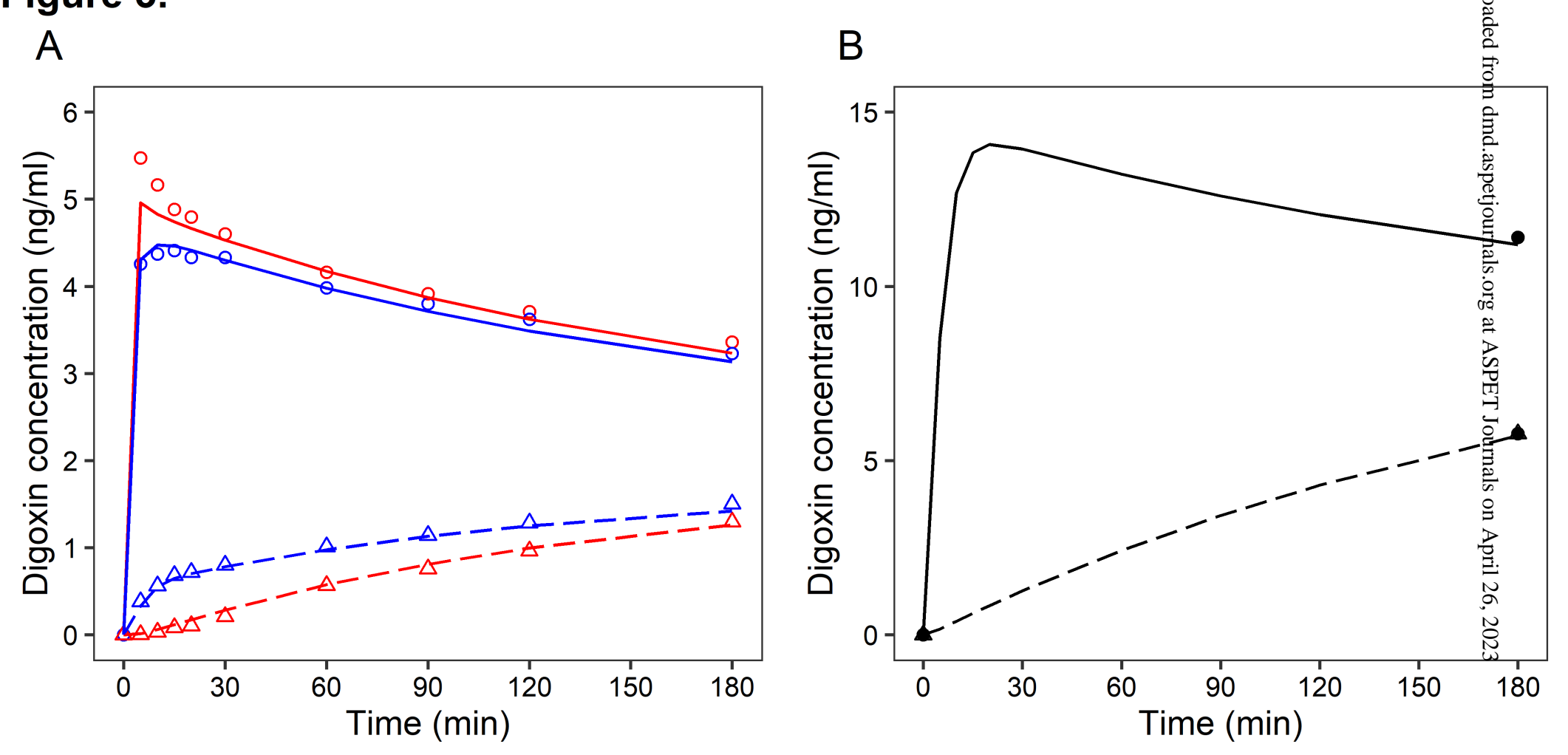
Figure 4.

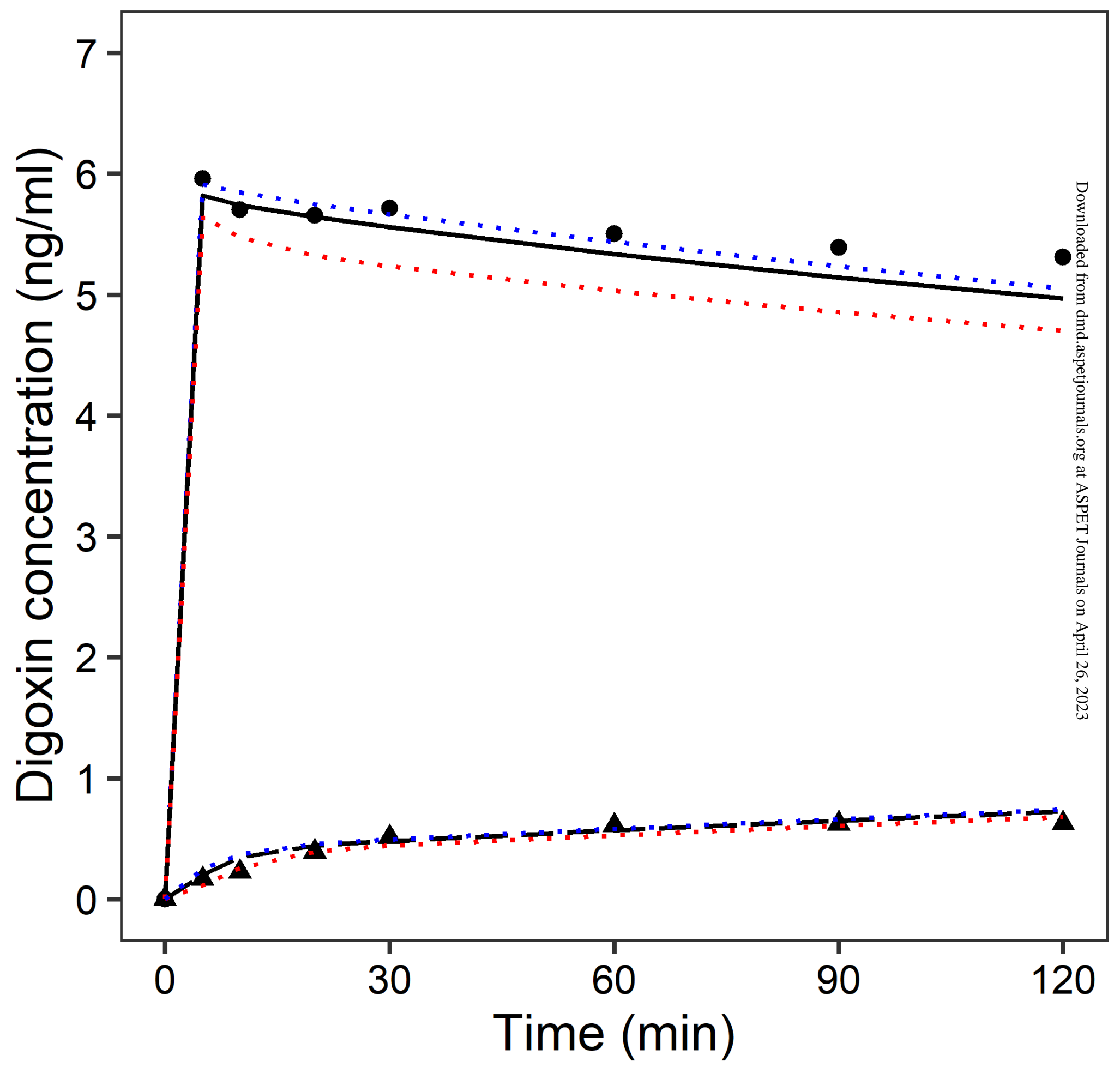


Figure 6.

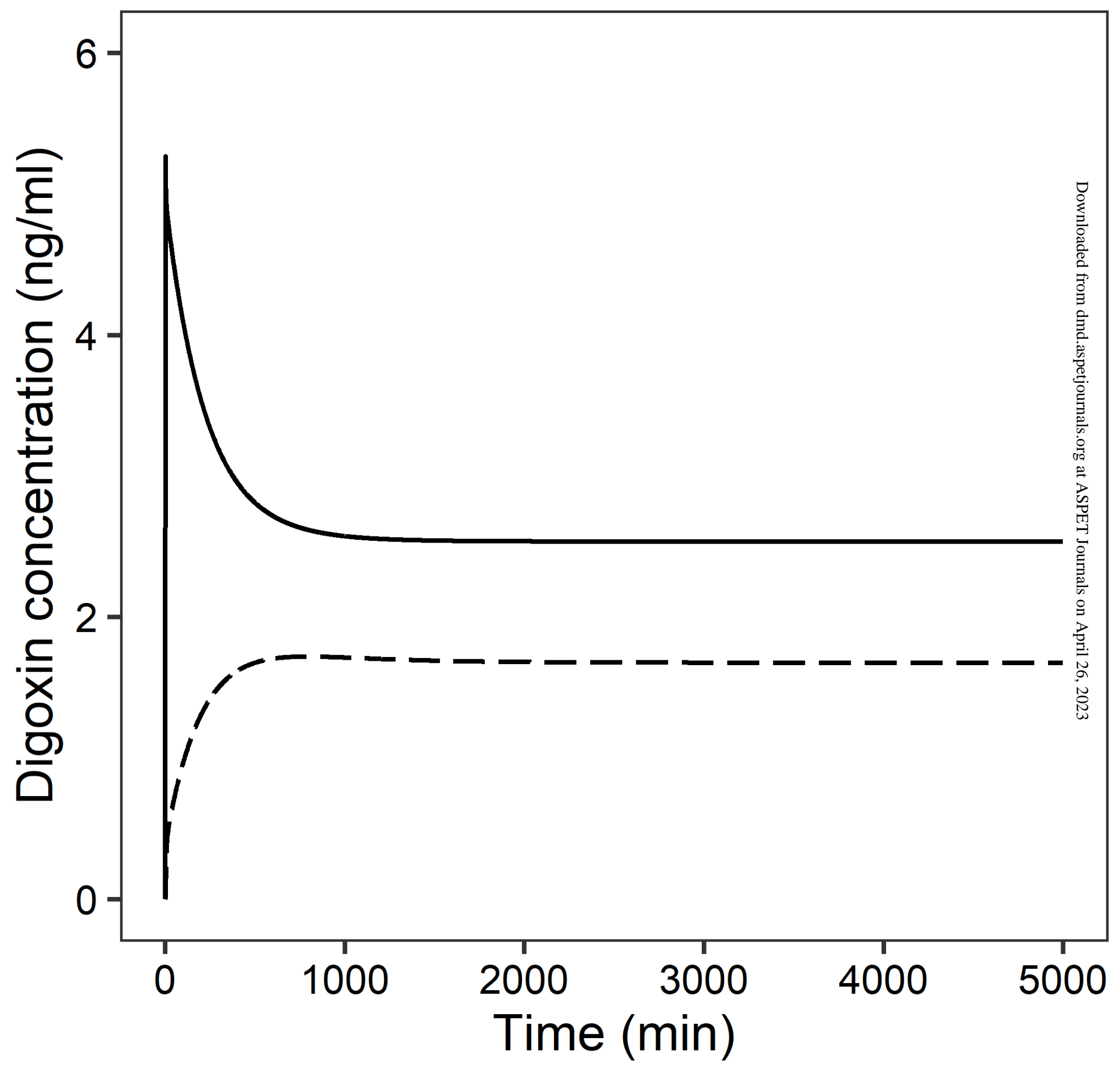


Figure 7.

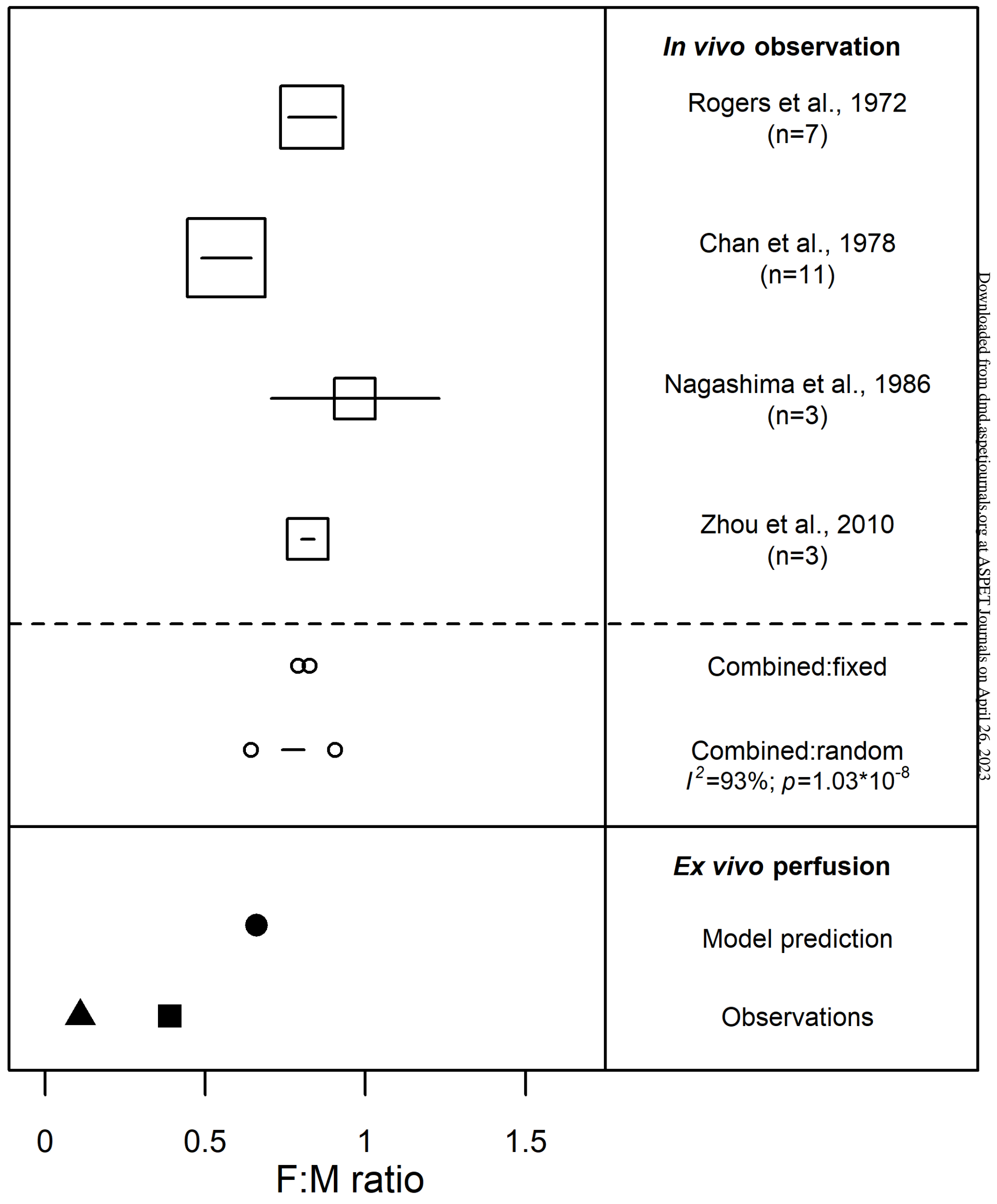


Figure 8.

A

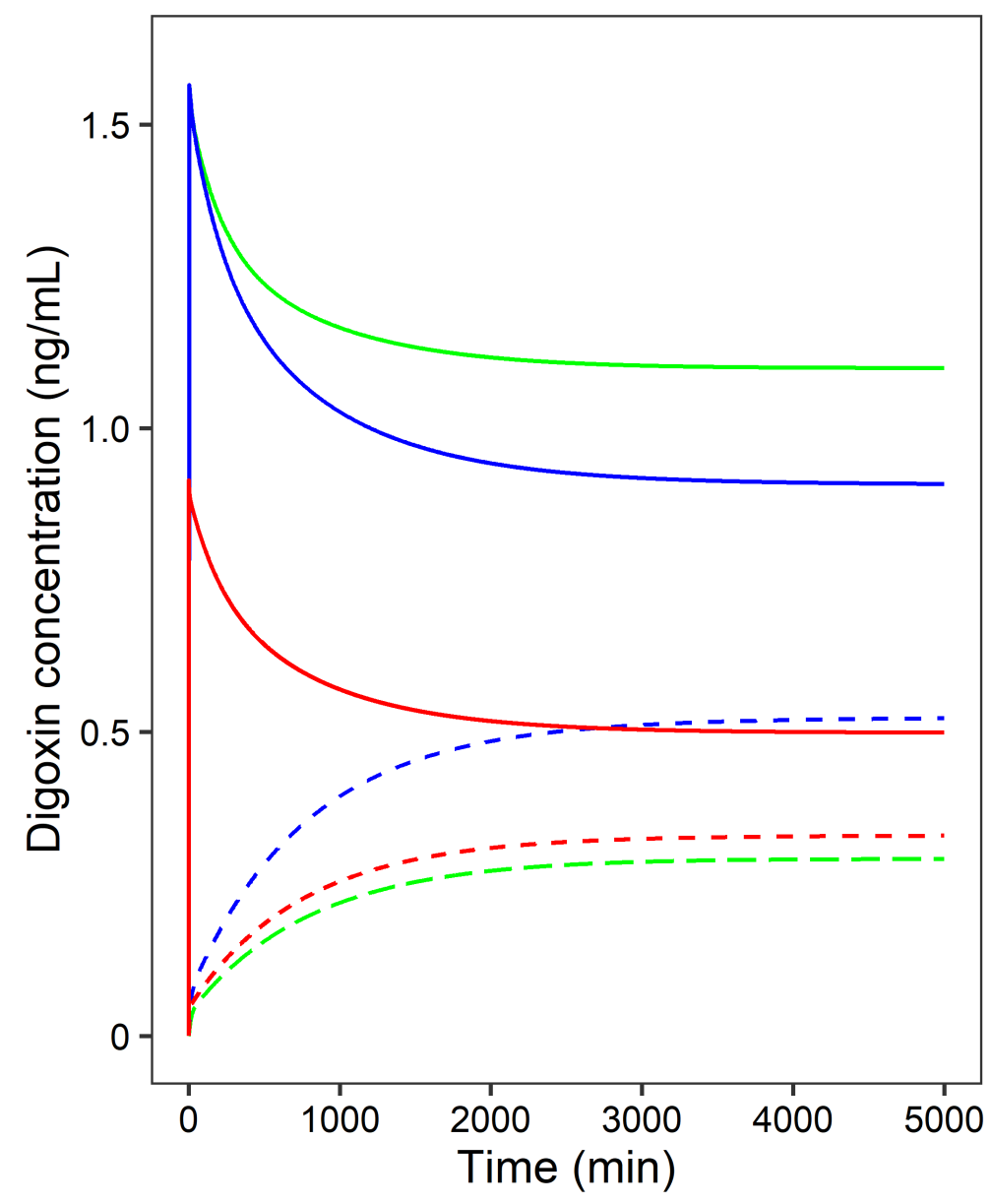

C

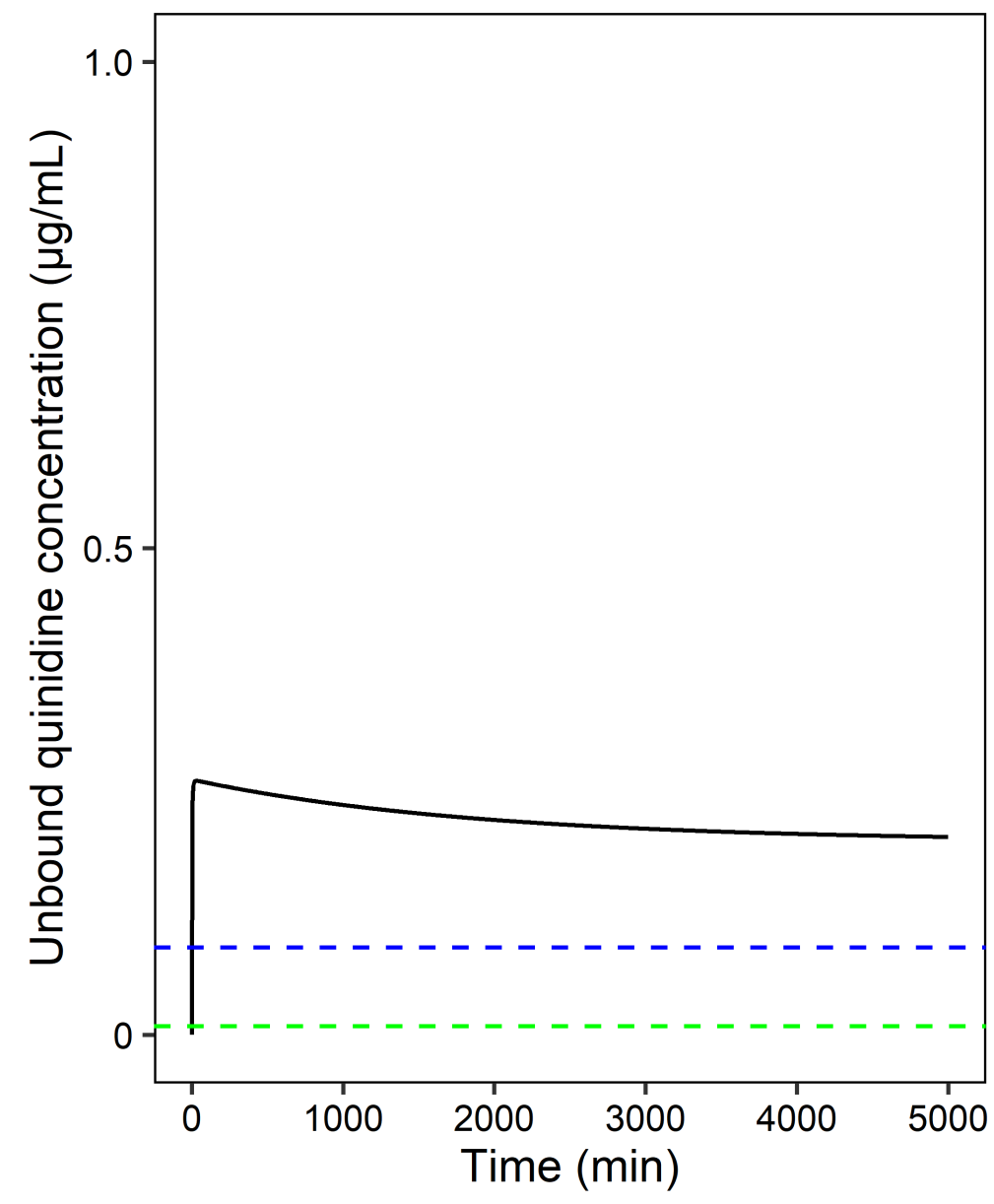

B

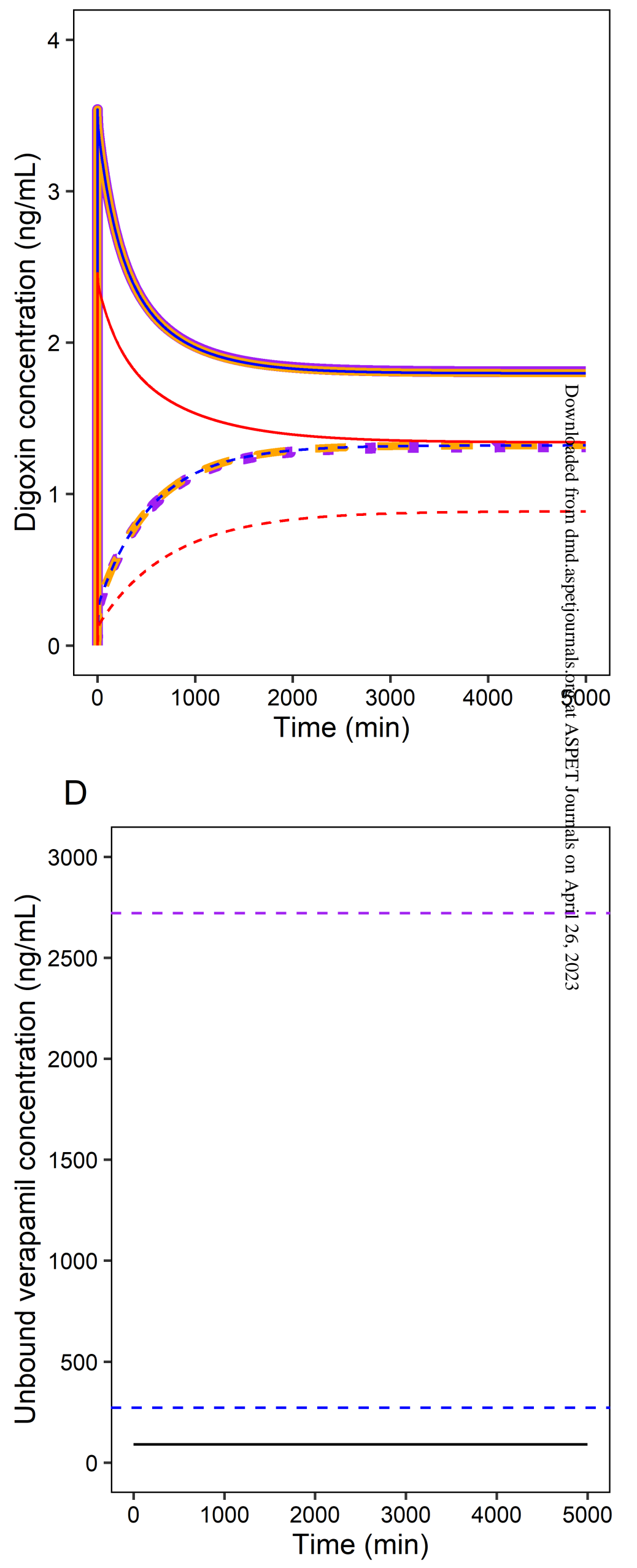

